\title{
Seismic Analysis on Recycled Aggregate Concrete Frame Considering Strain Rate Effect
}

\author{
Changqing Wang ${ }^{1,2,3)}$, Jianzhuang $X^{1 a o^{1), *}}{ }^{\text {, and Zhenping Sun }}{ }^{1,4)}$
}

(Received October 19, 2015, Accepted May 7, 2016, Published online May 27, 2016)

\begin{abstract}
The nonlinear behaviors of recycled aggregate concrete (RAC) frame structure are investigated by numerical simulation method with 3-D finite fiber elements. The dynamic characteristics and the seismic performance of the RAC frame structure are analyzed and validated with the shaking table test results. Specifically, the natural frequency and the typical responses (e.g., storey deformation, capacity curve, etc.) from Model 1 (exclusion of strain rate effect) and Model 2 (inclusion of strain rate effect) are analyzed and compared. It is revealed that Model 2 is more likely to provide a better match between the numerical simulation and the shaking table test as key attributes of seismic behaviors of the frame structure are captured by this model. For the purpose to examine how seismic behaviors of the RAC frame structure vary under different strain rates in a real seismic situation, a numerical simulation is performed by varying the strain rate. The storey displacement response and the base shear for the RAC frame structure under different strain rates are investigated and analyzed. It is implied that the structural behavior of the RAC frame structure is significantly influenced by the strain rate effect. On one hand, the storey displacements vary slightly in the trend of decreasing with the increasing strain rate. On the other hand, the base shear of the RAC frame structure under dynamic loading conditions increases with gradually increasing amplitude of the strain rate.
\end{abstract}

Keywords: recycled aggregate concrete (RAC), frame structure, seismic analysis, strain rate effect, finite element model, shaking table test.

\section{Introduction}

In civil engineering, almost all concrete structures will inevitably encounter dynamic loads during their design lifetime. For example, structures may suffer from earthquake loading. Because of their unpredictability and destructive nature, these kinds of loading always become important factors in dominating structural design. Concrete is a typical rate-dependent material. Therefore, the strength, stiffness and ductility (or brittleness) of concrete are affected by loading rates. The strain rate at critical sections may be up to $10^{-1} / \mathrm{s}$ for reinforced concrete structures subjected to strong earthquake ground motion excitations (Bischoff and Perry 1991). The properties of structural materials at dynamic loading conditions will be

\footnotetext{
${ }^{1)}$ College of Civil Engineering, Tongji University, Shanghai 200092, China.

*Corresponding Author; E-mail: jzx@tongji.edu.cn

${ }^{2)}$ Postdoctoral Mobile Research Station, College of Material Science and Engineering, Tongji University, Shanghai, China.

${ }^{3)}$ Nanyang Normal University, Nanyang 473000, China.

${ }^{4)}$ College of Material Science and Engineering, Tongji University, Shanghai, China.
}

Copyright $($ The Author(s) 2016. This article is published with open access at Springerlink.com different from those at static loading conditions (Wakabayashi et al. 1984; Shing and Mahin 1988). The research of rate-dependency of concrete started in 1917 with Abrams' dynamic compressive test (1917). Based on the experimental results, Norris et al. (1959) proposed an empirical formula and predicted that the compressive strengths should increase by up to 33,24 and $17 \%$ as compared with the static strength when the strain rate was $3,0.3$ and $0.1 / \mathrm{s}$, respectively. Atchley and Furr (1967) reported that the dynamic compressive strength of concrete increased by between 25 and $38 \%$. A number of research efforts have been devoted to the effects of high strain rate $(>1 / \mathrm{s})$ on structural materials under impact loading in the past few decades (Le and Bailly 2000; Lin et al. 2008). Recent investigation by Cotsovos and Pavlovic (2006) indicated that the application of high rates of uniaxial compressive loading on concrete prisms results in these specimens exhibiting high rates of axial and lateral deformation which, in turn, triggers the development of significant inertia forces.

The dynamic tensile tests of concrete are more difficult to perform and there are limited results available. Zielinski et al. (1981) studied the behaviour of concrete subjected to uniaxial impact tensile loading and found that the ratios of impact to static tensile strengths were between 1.33 and 2.34 for various concrete mixes. Oh (1987) presented a realistic non-linear stress-strain model that can describe the dynamic tensile behaviour of concrete. In that model, an equation was proposed to predict the increase of tensile strengths. Cadoni et al. (2001) studied the effect of strain rate on the tensile 
behaviour of concrete at different relative humidity levels. The numerical analysis performed by Cotsovos and Pavlovic (2008) reveals that at high rates of tensile loading only the upper region of the concrete specimen deforms whereas the rest remains practically unaffected by the application of the external load. Furthermore, the behaviour of the concrete prisms under high rates of uniaxial tensile loading is affected by a number parameters related to the structural characteristics of the prisms such as mass, strength, and stiffness. Experimental investigation on dynamic tensile and compressive tests by Xiao et al. (2008) indicate that the tensile and compressive strengths of concrete increase with the loading rate. The initial tangential modulus and the critical strain of concrete in tension are independent of strain rate but those in compression slightly increase with the strain rate. Poisson's ratio of concrete in both tension and compression is not obviously dependent of loading rate. Some researches (Soroushian and Choi 1987; Chang and Lee 1987; RestrepoPosada et al. 1994; Malvar and Crawford 1998) on the effects of strain rate on the steel material have been conducted. The conclusions drawn from their studies are that the yield strength and ultimate strength enhance as the strain rate increases, the elastic modulus is not influenced by the strain rate variations, and the strain-rate effects are inversely proportional to the strength of steel. The effects of strain rate on the reinforcing steel were investigated experimentally by $\mathrm{Li}$ and $\mathrm{Li}$ (2012). Based on the test results, the dynamic increasing factors which are functions of strain rate and quasi-static yield strength of steel are built. In order to study the dynamic behaviour of reinforced concrete structures affected by strain rate when subjected to seismic loading, a strain rate dependent material model for concrete was proposed by Pandey et al. (2006) for analysis of 3-D reinforced concrete structures under transient dynamic loads.

The material property of recycled aggregate (Hansen 1986), the mechanical behavior of recycled aggregate concrete (RAC) (ACI Committee 555 2002), and the constitutive relationship of stress-strain of RAC under static loadings (Xiao et al. 2005) have been experimentally studied and theoretically analyzed. It has been found that there is slight difference in mechanical properties between RAC and natural aggregate concrete. A large number of research works indicate that RAC can be used in civil engineering applications; however, knowledge of the seismic behavior of RAC is insufficient and incomplete. This is further confirmed by recent experimental studies of the mechanical behavior of structural members made of RAC (Fathifazl et al. 2009; Xiao et al. 2012a, b; Ajdukiewicz and Kliszczewicz 2007). It may be noted that most of the above studies on RAC were carried out under static or quasi-static loadings. A long-standing interest in the response of concrete subjected to dynamic loads stems from the widespread use of concrete structures in seismic region. However, only a few works have been reported on the mechanical behavior of RAC under dynamic loading conditions. Xiao et al. (2014) performed a series of experiments on modeled RAC under uniaxial compressive loading condition, and observed compressive strength and elastic modulus to increase with the increase of strain rate. The split Hopkinson pressure bar tests of RAC under compression loading condition were carried out by Lu et al. (2014) and Xiao et al. (2015). Results show that, impact properties of RAC exhibit strong strain rate dependency, and increase approximately linearly with the strain rate. The compressive behaviour of RAC with different recycled coarse aggregate (RCA) replacement percentages was experimentally investigated under quasistatic to high strain rate loading by Xiao et al. (2015), and the strain rate effects on the failure pattern, compressive strength, initial elastic modulus and peak strain were studied.

The dynamic mechanical behaviors of RAC structures at high strain rate representative of seismic conditions were also investigated experimentally in recent years. Zhang et al. (2014) performed shaking table tests on four $1 / 5$ scaled RAC frame-shear wall structures with concealed bracing detail. The dynamic characteristics, dynamic response and failure mode of each model were compared and analyzed. Shaking table tests on a full scale model of RAC block masonry building with the tie column + ring beam + cast-in-place slab system was carried out by Wang and Xiao (2012). The dynamic characteristics, the seismic performance, and the damage assessment of RAC frame structure were analyzed under different earthquake levels.

Economic considerations and the seismic design philosophy indicate that building structures are able to resist major earthquakes without collapse but with some structural damage. Therefore it is imperative that seismic design is based on nonlinear analysis of structures. For the nonlinear analysis of reinforced concrete structures a variety of models have been considered. For the early research on the nonlinear analysis, the material models which were obtained at low strain rates without strain rate effect included were generally adopted to predict behavior of the structures under seismic conditions which were characterized by high strain rates. There is little evidence of the stress-strain behavior considering strain rate dependency of RAC for large scale loaded specimens finding a place in the seismic nonlinear analysis of RAC structures. This paper examines the influence of the strain rate effect on the seismic response of an RAC frame structure.

In this study, the tested structure applied to evaluate the seismic behavior with the influence of the strain rate of material is a one-fourth scaled, two-bay, two-span and sixstorey RAC frame. The RAC members are modelled using the flexibility-based fiber beam-column element with the material models of Kent-Scott-Park concrete model and the hysteretic material steel model. To examine the influence of the strain rate on dynamic response of the structure the strain rate effects for RAC and reinforcing steel have been taken into account in the Kent-Scott-Park model and the hysteretic model, respectively, by applying the dynamic increase factors (DIFs) which were derived by a test as well as from CEB (1993) on the test results basis. The dynamic characteristics (e.g., natural frequency) and the seismic behaviors (e.g., storey deformation, capacity curve, etc.) of the RAC frame structure are analyzed and discussed systematically by examining both the model with the strain rate effect included 
and the model with the strain rate effect excluded, and compared with the shaking table test results. For the purpose to examine how the seismic behaviors of the RAC frame structure vary under different strain rates in a real seismic situation, a numerical simulation is performed by varying the parameters of strain rates. The storey displacement response and the base shear for RAC frame structure under different strain rates are investigated and analyzed. It is implied that the structural behavior of RAC frame structure is significantly influenced by the strain rate effect. Firstly, the storey displacements vary slightly in the trend of decreasing with the increasing strain rate. Secondly, the base shear of the RAC frame structure under dynamic loading conditions increases with gradually increasing amplitude of strain rate.

\section{Strain Rate-Dependent Material Model}

\subsection{Strain Rate-Dependent Model of Concrete}

In this study, the dynamic mechanic tests of RAC under dynamic loading conditions with strain rates of $1 \times 10^{-5}$, $1 \times 10^{-3}$, and $1 \times 10^{-2} / \mathrm{s}$ were performed at the test setup of MTS 815 concrete test system. For the specimen, shown in Fig. 1, the dimension of cross section is $150 \mathrm{~mm} \times$ $150 \mathrm{~mm}$, and the longitudinal size is $450 \mathrm{~mm}$. The test setup in the dynamic tests is shown in Fig. 2 and the test model is exhibited in Fig. 3.

Through the dynamic tests, the complete curves of stressstrain relationship for RAC with replacement ratios (R) of 0 and $100 \%$ are plotted in Fig. 4a, b, respectively. Based on these stress-strain curves, the characteristic parameters such as the compressive peak stress and critical peak strain, etc., can be easily identified.

Based on regression analysis of the experimental test data from dynamic tests of RAC, the relationship between the DIF of compressive strength and the strain rate is established

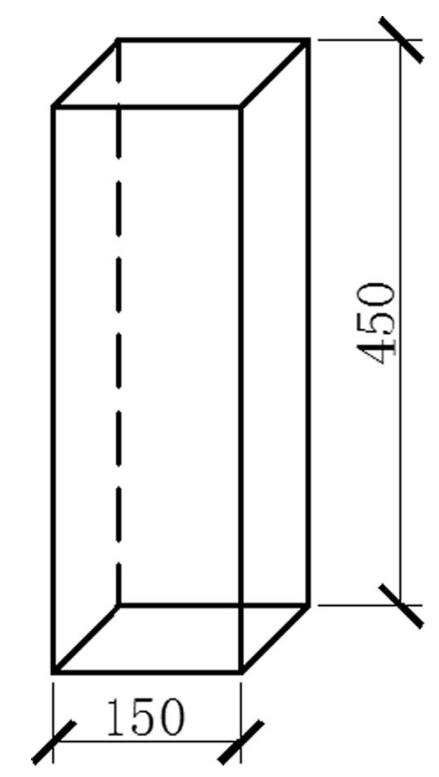

Fig. 1 Dimension of specimen.

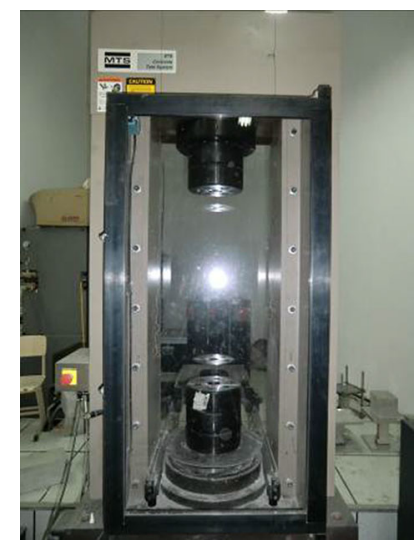

Fig. 2 Test setup.

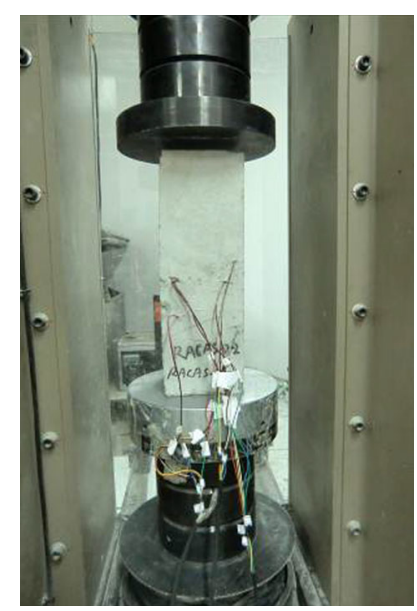

Fig. 3 Overview of test model.

and illustrated in Fig. 5, and the corresponding model of DIF is preliminary proposed and expressed in the following:

$$
k_{f_{c}}=\frac{f_{c d}^{\prime}}{f_{c}^{\prime}}=\left(\frac{\dot{\varepsilon}_{c}}{\dot{\varepsilon}_{c 0}}\right)^{\alpha}
$$

with

$$
\alpha=6.664 \times \frac{1}{6.943+8.656 f_{c}}
$$

The DIF formula proposed in this study for RAC is valid for strain rates at a constant range of approximately $1 \times$ $10^{-5}<\dot{\varepsilon}_{c}<1 \times 10^{-1} / \mathrm{s}$ under compression. Where, $k_{f_{c}}$ is the DIF for the compressive strength of concrete, $f_{c d}^{\prime}$ and $f_{c}^{\prime}$ represent the prism compressive strength of concrete under dynamic loading and quasi-static loading conditions in $\mathrm{MPa}$, respectively, $f_{c}$ stands for the nominal compressive strength of RAC (MPa), which is equal to $30 \mathrm{MPa}$ in this study, $\dot{\varepsilon}_{c}$ is the compressive strain rate of concrete $(1 / \mathrm{s}), \dot{\varepsilon}_{c o}$ is the quasistatic compressive strain rate of RAC, which is equal to $3.04 \times 10^{-5}$ in this study.

The discreteness can be observed in testing mechanical indexes of concrete, especially for RAC because of the different sources of RCA which has been proved in previous conclusions by researchers (Xiao 2008), although 81 test units are carried out in the dynamic tests by the authors. The 


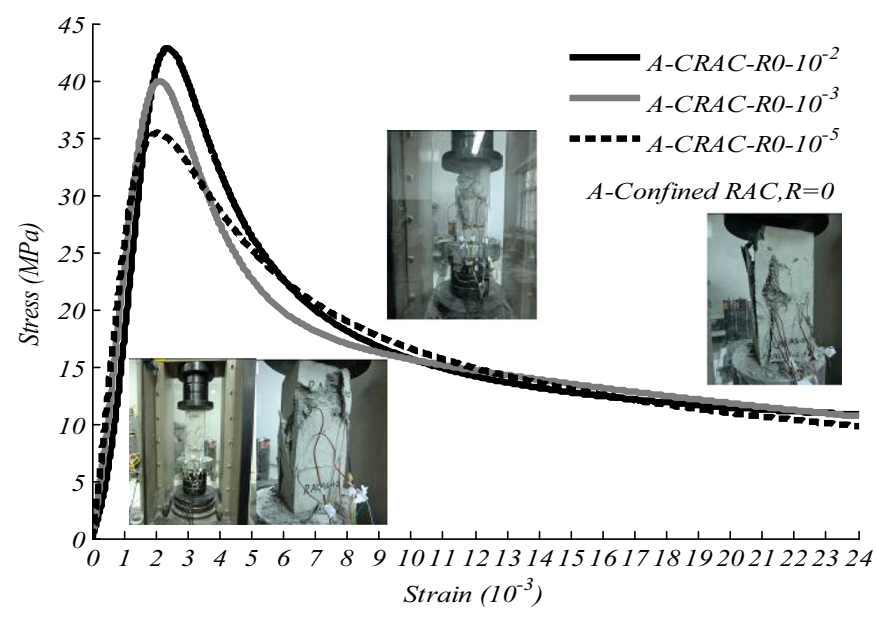

(a) $\mathrm{R}=0$

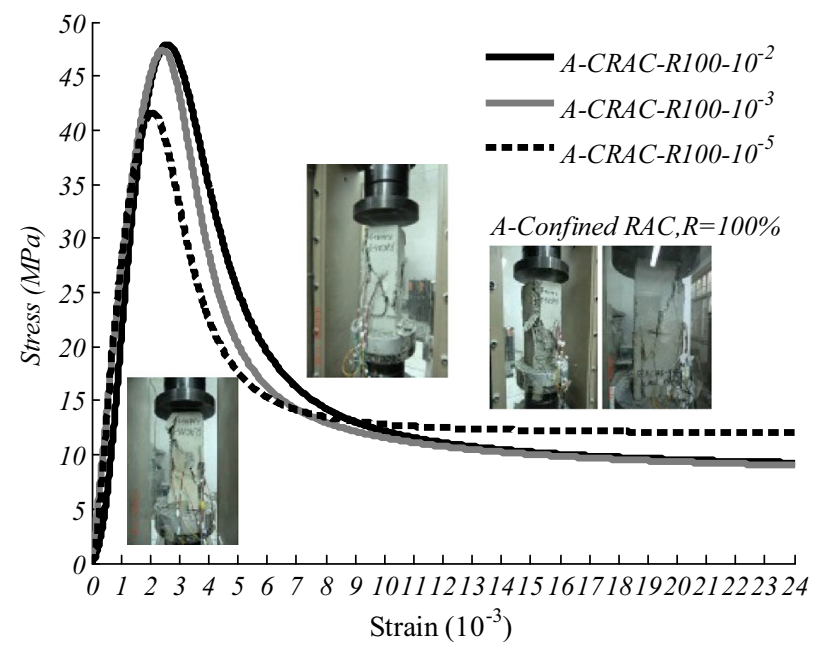

(b) $\mathrm{R}=100 \%$

Fig. 4 Completed curve of stress-strain relationship for RAC under compression.

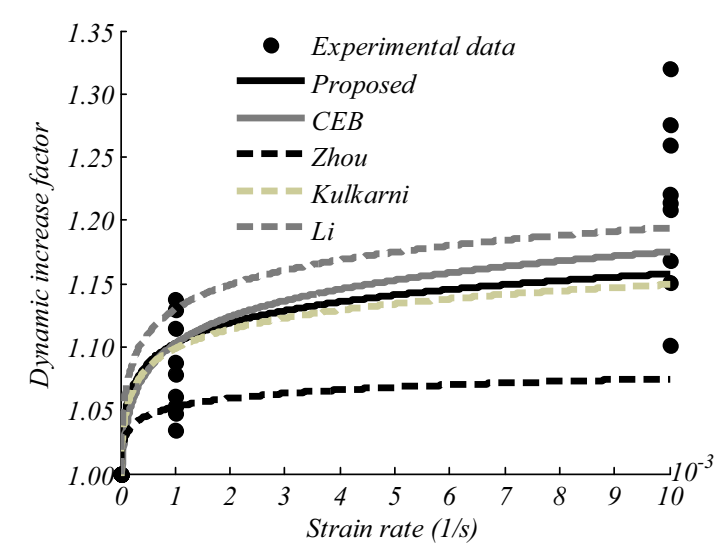

Fig. 5 DIF of compressive strength of RAC.

proposed DIF function model is compared to those from other researchers (Li and Li 2012; The Euro-International Committee for Concrete (CEB) 1993; Zhou and Hao 2008; Kulkarni and Shah 1998) and shown in Fig. 5. Comparing the enhancement values of the compressive peak stress of RAC calculated from the empirical formulas of DIF under different strain rates, it is implied that the distribution of the calculation curve of DIF from the proposed model is consistent with those from other function models. The calculation values of DIF given by CEB are more close to those from the proposed model. Therefore, the proposed formula of DIF of the compressive peak stress for RAC is reasonable and applicable to describe the changing law of compression strength of RAC subjected to the excitation of the dynamic loads.

For a given strain rate the tensile strength under the dynamic loading condition advised by CEB (1993) is adopted in this study and defined as follows

$$
k_{f t}=\frac{f_{t d}}{f_{t}}=\left(\frac{\dot{\varepsilon}_{t}}{\dot{\varepsilon}_{t o}}\right)^{1.016 \delta_{s}}
$$

with

$$
\delta_{s}=\frac{1}{10+6 \frac{f_{c}^{\prime}}{10}}
$$

The DIF formula proposed in this study for RAC is valid for strain rates at a constant range of approximately $1 \times$ $10^{-5}<\dot{\varepsilon}_{c}<1 \times 10^{-1} / \mathrm{s}$ under tension. Where, $k_{f t}$ is the DIF for the tensile strength of concrete, $f_{t d}$ and $f_{t}$ represent the tensile strength of concrete under the dynamic and quasistatic loading conditions in $\mathrm{MPa}$, respectively, $f_{c}^{\prime}$ represents the compressive strength of concrete under quasi-static loading conditions $(\mathrm{MPa}), \dot{\varepsilon}_{t}$ is the tensile strain rate of concrete $(1 / \mathrm{s}), \dot{\varepsilon}_{t o}$ is the quasi-static tensile strain rate of concrete, which is equal to $3.04 \times 10^{-5}$ in this study.

Critical strain is defined as the strain when the stress reaches the peak value. Bischoff and Perry (1991) summarized a wide range of concrete with various static strengths and strain rates, showing the significant increases in compressive critical strain were observed during impact loading, although these increases were generally less than those observed for strength in the literature by Chen et al. (2013). According to Bischoff and Perry (1991), the extension of cracking required for failure increases with the strain rate. The increased compressive critical strain may also be explained by the lateral confinement which results in the formation of significant amounts of microcracks, but prevents the formation of macrocracks (Lai and Sun 2009). In this study, based on regression analysis of experimental test data from dynamic tests of RAC, the relationship between the DIF of the compressive critical strain of RAC and the strain rate is displayed in Fig. 6, and the corresponding model of DIF is preliminary proposed in the following form:

$$
\begin{aligned}
& k_{\varepsilon_{c}}=\frac{\varepsilon_{d 0}}{\varepsilon_{c 0}}=\left(\frac{\dot{\varepsilon}_{c}}{\dot{\varepsilon}_{c 0}}\right)^{\phi} \\
& \phi=0.01597
\end{aligned}
$$

where $k_{\varepsilon c}$ is the DIF for the compressive critical strain of concrete, $\varepsilon_{d 0}$ and $\varepsilon_{c 0}$ are the compressive critical strain of concrete under the dynamic and quasi-static loading conditions, respectively, other symbols are the same as in Eq. (1). 
The model implemented in this study takes into account the effect of concrete confinement on the monotonic envelope curve in compression is illustrated in Fig. 7. The successive degradation of the stiffness of both reloading and the unloading curves is included, because of the increasing values in compressive strain, the tension stiffness, and the hysteretic response under seismic conditions (Yassin and Hisham 1994). The monotonic envelope curve of concrete in compression follows the model by Kent and Park (1971) that was later extended by Scott et al. (1982). In this study, the effect of the strain rate has been taken into account in this Kent-Scott-Park model by applying the DIFs $\left(k_{f}, k_{\varepsilon}\right)$ which were derived by CEB (1993). Thus, the RAC compressive stress-strain relation, in which the strain rate effect is considered, is proposed as follows:

$$
\text { Region OA: } \sigma_{c}=K_{d} f_{c d}^{\prime}\left[2\left(\frac{\varepsilon_{c}}{\varepsilon_{d o}}\right)-\left(\frac{\varepsilon_{c}}{\varepsilon_{d o}}\right)^{2}\right] \quad\left(\varepsilon_{c} \leq \varepsilon_{d 0}\right)
$$

$$
\begin{aligned}
& \text { Region AB: } \sigma_{c}=K_{d} f_{c d}^{\prime}\left[1-Z_{d}\left(\varepsilon_{c}-\varepsilon_{d o}\right)\right] \\
& \quad\left(\varepsilon_{d 0}<\varepsilon_{c} \leq \varepsilon_{2 d 0}\right)
\end{aligned}
$$

Region BC: $\sigma_{c}=0.2 K_{d} f_{c d}^{\prime} \quad\left(\varepsilon_{c}>\varepsilon_{2 d 0}\right)$

The corresponding tangent modulus for each region is listed as follows:

$$
\begin{aligned}
& E_{t d}=\frac{2 K_{d} f_{c d}^{\prime}}{\varepsilon_{d o}}\left(1-\frac{\varepsilon_{c}}{\varepsilon_{d o}}\right) \quad\left(\varepsilon_{c} \leq \varepsilon_{d 0}\right) \\
& E_{t d}=-Z_{d} K_{d} f_{c d}^{\prime} \quad\left(\varepsilon_{d 0}<\varepsilon_{c} \leq \varepsilon_{2 d 0}\right) \\
& E_{t d}=0 \quad\left(\varepsilon_{c}>\varepsilon_{2 d 0}\right)
\end{aligned}
$$

where

$$
\begin{aligned}
& f_{c d}^{\prime}=k_{f c} f_{c}^{\prime} \\
& \varepsilon_{d 0}=0.002 K_{d} k_{\varepsilon c} \\
& K_{d}=\left(1+\frac{\rho_{s} f_{y h}}{f_{c d}^{\prime}}\right)
\end{aligned}
$$

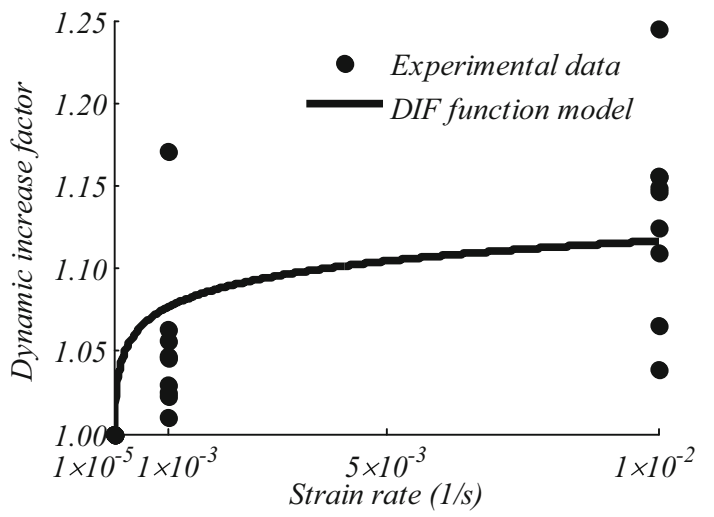

Fig. 6 DIF of the compressive critical strain of RAC.

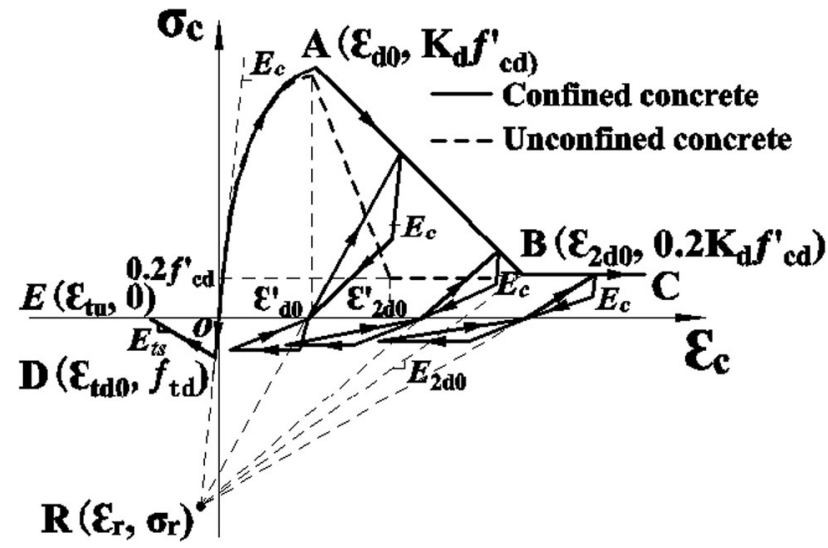

Fig. 7 Modified Kent-Scott-Park model.

$$
Z_{d}=\frac{0.5}{\frac{3+0.29 f_{c d}^{\prime}}{145 f_{c d}^{\prime}-1000}+0.75 \rho_{s} \sqrt{\frac{h^{\prime}}{s_{h}}}-0.002 K_{d}}
$$

$\sigma_{c}$ and $\varepsilon_{c}$ are the compressive stress and the corresponding strain, respectively, $\varepsilon_{d 0}$ is the compressive critical strain under the dynamic loads, $\varepsilon_{2 d 0}$ is the strain corresponding to $20 \%$ of the compressive peak stress at the descending branch of the stress-strain curve under the dynamic loads, $f_{c}^{\prime}$ and $f_{c d}^{\prime}$ stand for the quasi-static and dynamic axial compressive strength of concrete in $\mathrm{MPa}$, respectively, $K_{d}$ is a factor which accounts for the strength increase due to the confinement and the strain rate effect of concrete, $Z_{d}$ is the strain softening slope considering the strain rate effect of concrete, $f_{y h}$ is the dynamic yield strength of stirrups in $\mathrm{MPa}$, $\rho_{s}$ is the volume ratio of the hoop reinforcement to the concrete core measured to outside of stirrups, $h^{\prime}$ is the width of concrete core measured to outside of stirrups, and $s_{h}$ is the center to center spacing of stirrups or hoop sets. The cyclic unloading and reloading behavior is represented by a set of straight lines as shown in Fig. 7 which shows that hysteretic behavior occurs under both tension and compression stress.

The ultimate strain of concrete confined by stirrup-ties $\varepsilon_{u}$ is given by Eq. (17) which was suggested by Scott et al. (1982).

$$
\varepsilon_{u}=0.004+0.9 \rho_{s}\left(\frac{f_{y h}}{300}\right)
$$

In the model the rate-dependent monotonic tensile stressstrain relation of concrete is describe by the following equations:

$$
\begin{aligned}
& \sigma_{t}=E_{t d} \varepsilon_{t} \quad \varepsilon_{t} \geq \varepsilon_{t d 0} \\
& \sigma_{t}=f_{t d}+E_{t s}\left(\varepsilon_{t}-\varepsilon_{t d 0}\right) \quad \varepsilon_{t u} \leq \varepsilon_{t}<\varepsilon_{t d 0}
\end{aligned}
$$

with

$$
\begin{gathered}
f_{t d}=-0.6228 \sqrt{k_{f t} f_{c}^{\prime}} \\
E_{t d}=\frac{f_{t d}}{\varepsilon_{t d 0}} \quad\left(\varepsilon_{t} \leq \varepsilon_{t d 0}\right)
\end{gathered}
$$


where $\sigma_{t}$ and $\varepsilon_{t}$ are the tension stress and the corresponding strain, respectively, $\varepsilon_{t d 0}$ is the tensile critical strain of concrete, $\varepsilon_{t u}$ is the strain at the point where the tensile stress is reduced to zero, which is assumed to be kept unchanged under the dynamic and quasi-static loadings, $f_{t d}$ is the tensile strength of concrete under the dynamic condition in MPa, $f_{c}^{\prime}$ stands for the quasi-static axial compressive strength of concrete in $\mathrm{MPa}, E_{t s}$ is the tension stiffening modulus that depends on numerical and physical parameters. The modulus $E_{t s}$ controls the degree of tension stiffening.

According to the results by earlier researchers (Xiao et al. 2008; Malvar and Ross 1998), it is observed that, in the range of strain rate from $10^{-5}$ to $10^{-2} / \mathrm{s}$, the effect of strain rate on the critical strain value of concrete in tension is limited. Therefore, DIF of the tensile peak strain, i.e., the ratio of the tensile peak strain at dynamic loading rate to that at quasi-static loading rate, is assumed to be equal to 1.0 in the present work.

In this study, the quasi-static mechanical properties of RAC were measured. Thus, the dynamic stress-strain relation of the modified Kent and Park concrete model can be determined by the above equations, and the tested mechanical properties of RAC under the quasi-static loadings related to the model are listed in Table 1 .

\subsection{Strain Rate-Dependent Model of Steel}

Based on experimental studies and numerical analyses, some empirical formulae of DIF of reinforcing steel are developed. In this study, the DIF formula for reinforcing steel derived by CEB (1993) is adopted and recalled here.

The DIF formula proposed by CEB (1993) for reinforcing steel is valid for strain rates at a constant range of approximately $5 \times 10^{-5}<\dot{\varepsilon}_{S}<10 / \mathrm{s}$, which is given as follows

$$
\begin{aligned}
& k_{s y}=\frac{f_{y d}}{f_{y}}=1.0+\left(\frac{6.0}{f_{y}}\right) \ln \left(\frac{\dot{\varepsilon}_{s}}{\dot{\varepsilon}_{s 0}}\right) \\
& k_{s u}=\frac{f_{u d}}{f_{u}}=1.0+\left(\frac{6.0}{f_{u}}\right) \ln \left(\frac{\dot{\varepsilon}_{s}}{\dot{\varepsilon}_{s 0}}\right)
\end{aligned}
$$

where $k_{s y}$ and $k_{s u}$ are the DIF of the yield and ultimate strength of reinforcing steel, respectively, $f_{y}$ and $f_{y d}$ represent the quasi-static and dynamic yield strength of steel in MPa, respectively, $f_{u}$ and $f_{u d}$ denote the quasi-static and dynamic ultimate strength of steel in MPa, respectively, $\dot{\varepsilon}_{s}$ is the strain rate of steel, $\dot{\varepsilon}_{s 0}$ means the quasi-static strain rate of steel, which is equal to $3.04 \times 10^{-5}$ in this study.

Several models were proposed to represent the stressstrain relationship of steel reinforcements (Soroushian and Choi 1987; Chang and Lee 1987; Restrepo-Posada et al. 1994; Malvar and Crawford 1998). In this study, the hardening and softening of strain, the pinching effect of force and deformation, and unloading stiffness degradation are considered in this material model. The material model (Hognestad 1951; Filippou et al. 1992) for the steel bar is shown in Fig. 8, and the effect of the strain rate has been taken into account in this hysteretic model by applying the DIFs $k_{s y}$ and $k_{s u}$ which are derived by CEB (1993). Thus, the stress-strain relation of the hysteretic model is modified by considering the DIF $k_{s y}$ in the yield strengths $\left(s_{1 p}\right.$, and $\left.s_{1 n}\right)$ and the critical strains at the yield strengths $\left(e_{1 p}\right.$ and $\left.e_{1 n}\right)$, as well as $k_{s u}$ in the ultimate strengths $\left(s_{3 p}\right.$ and $\left.s_{3 n}\right)$. The other characteristic parameters are assumed to be unchanged. The slope of each branch of the hysteretic model of the reinforcing steel is given by the above equations.

In this study, the quasi-static mechanical properties of fine iron wires including the yield strength and the initial elastic modulus were tested. The stress-strain relation of the modified hysteretic model can be determined by the above equations, and the tested material properties of the fine iron wires under the quasi-static loadings related to the steel model are listed in Table 2.

In this study, the models of DIF are applied to the stressstrain relationships of reinforcement and RAC. In the numerical simulation, these constitutive models are used to simulate stirrups, longitudinal reinforcement, core concrete, and concrete cover, respectively.

\section{Numerical Modelling of RAC Frame Structure}

The present study concentrates on the discrete finite element models (FEMs), which are the best compromise between simplicity and accuracy in nonlinear seismic response studies and represent the simplest class of model that still provides significant insight into the seismic response of members and the whole structure.

Table 1 Measured material properties of RAC under the quasi-static loading.

\begin{tabular}{c|c|c|c}
\hline \multicolumn{2}{c|}{ Properties } & $\begin{array}{c}\text { Prism compressive strength } f_{c}^{\prime} \\
(\mathrm{MPa})\end{array}$ & $\begin{array}{c}\text { Elastic modulus } E_{c}(\mathrm{GPa}) \\
\text { Specimens }\end{array}$ \\
\cline { 2 - 4 } & Floor 1 & 35.31 & 24.38 \\
\cline { 2 - 4 } & Floor 2 & 42.36 & 26.18 \\
\cline { 2 - 4 } & Floor 3 & 35.96 & 24.25 \\
\cline { 2 - 4 } & Floor 4 & 31.86 & 23.24 \\
\cline { 2 - 4 } & Floor 5 & 27.89 & 21.13 \\
\hline
\end{tabular}




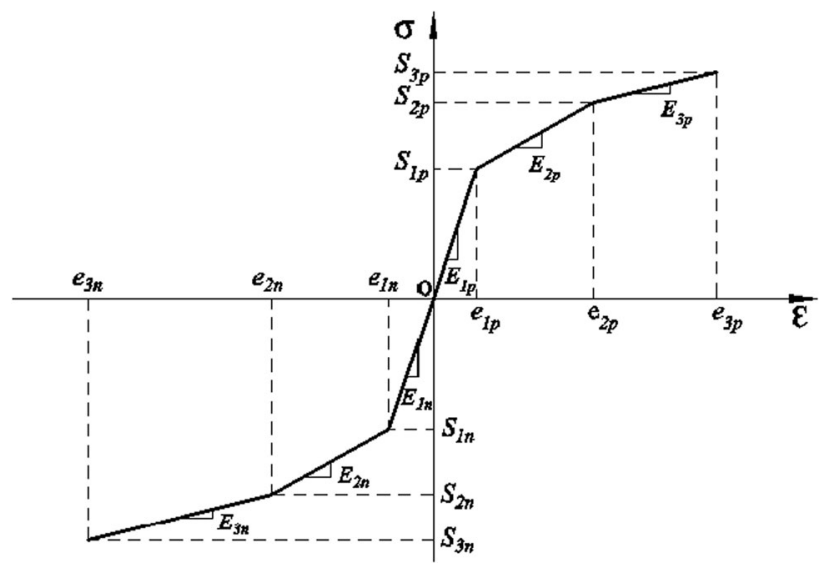

Fig. 8 Steel material model.

\subsection{Description of the Tested RAC Frame Model}

The tested model is a six-storey frame structure and was designed according to Chinese Standard GB 50011 (2010). The details of the general geometry are given in Fig. 9. An overview of the model after installation on the shaking table facility and the experimental set-up are shown in Fig. 10 (Xiao et al. 2012a). The Wenchuan earthquake wave (WCW, 2008, N-S) belonging to Type-II site soil was chosen. Considering the spectral density properties of TypeII site soil, El Centro earthquake wave (ELW, 1940, N-S) and Shanghai artificial wave (SHW) were also selected. The test procedure consisted of nine phases, namely, tests for peak ground acceleration (PGA) of $0.066,0.13 \mathrm{~g}$ (frequently occurring earthquake of intensity 8$), 0.185,0.264,0.370 \mathrm{~g}$ (basic occurring earthquake of intensity 8), 0.415, 0.55, $0.75 \mathrm{~g}$ (rarely occurring earthquake of intensity 8) and $1.17 \mathrm{~g}$ (rarely occurring earthquake of intensity 9).

\subsection{Strain Rate Calculation}

It is indicated from the damage pattern and the dynamic characteristics of the tested model (Xiao et al. 2012a) that the tested model suffered slight damage firstly and stepped into elastic-plastic state. With increasing intensity of shaking, the strain response of RAC becomes stronger. The maximum compressive strain reaches $1854 \times 10^{-6}$ in the $0.415 \mathrm{~g}$ test phase, and is close to the critical strain of RAC. It is inferred the structure suffers severe damage. The strain rate of RAC is calculated by numerical differentiation to the strain response history. With increasing input acceleration amplitudes, the stain rate of RAC increases progressively. The maximum concrete strain rate of RAC at the bottom of the corner column (Fig. 11) under three different earthquake excitations with PGA of $0.415-1.170 \mathrm{~g}$ is listed in Table 3.
The orders of the maximum strain rate of RAC at different peaks of acceleration are all at $10^{-2} / \mathrm{s}$, which is consistent with the results reported by Bertero et al. (1984). To simply the calculation, the mean value of the maximum strain rates which are to induce the most significant effect on mechanical behaviors of the structures is considered in this study, although the strain rate varies with the time. Therefore, the strain rates of $3.04 \times 10^{-5}, 3.04 \times 10^{-3}, 3.04 \times 10^{-2}$ and $3.04 \times 10^{-1} / \mathrm{s}$, which are regarded as being indicative of the strain rate expected during the response of reinforced concrete to earthquakes, are taken into account in the numerical simulation, respectively. The investigators (Bischoff and Perry 1991) found that there is no clear increase in strength of concrete or steel up to a strain rate of about $5 \times 10^{-5} / \mathrm{s}$. In this study the typical seismic response for the model with strain rate of $3.04 \times 10^{-5} / \mathrm{s}$ are defined as the quasi-static response and used as the reference values of the structural responses.

\subsection{Finite Element Model (FEM) of RAC Frame Structure}

The most promising models for the nonlinear analysis of reinforced concrete members are, presently, flexibility-based fiber elements. In this study, the spread plasticity fiber model is developed. The flexibility-based fiber element is subdivided into longitudinal fibers, which has two inherent advantages: (a) the reinforced concrete section behavior is derived from the uniaxial stress-strain behavior of the fibers and three-dimensional effects, such as concrete confinement by transverse steel can be incorporated into the uniaxial stress-strain relation, and (b) the interaction between bending moment and axial force can be described in a rational way. The fiber beam-column element originally formulated by Taucer et al. (1991) is a two-node, cubic, three-dimensional element with multiple fiber control sections. The formulation of the flexibility-based fiber beam-column element is based on the assumption of linear geometry, where plane sections remain plane and normal to the longitudinal axis during the element deformation history. While this hypothesis is acceptable for small deformation of elements composed of homogeneous material, it does not properly account for phenomena such as cracking and bond-slip which are characteristic of reinforced concrete elements. Investigation on effect of the bond-slip in the nonlinear analysis of RAC structures will be carried out in the future research work.

In order to study the effect of strain rate on the dynamic response of RAC structures, the dynamic responses of the RAC spatial frame are analyzed with the FE fiber models.

Table 2 Measured material properties of fine iron wires under the quasi-static loading.

\begin{tabular}{c|c|c|c|c|c}
\hline \multicolumn{2}{c|}{ Properties } & Diameter $(\mathrm{mm})$ & Yield strength $f_{y}(\mathrm{MPa})$ & $\begin{array}{c}\text { Ultimate strength } f_{u} \\
(\mathrm{MPa})\end{array}$ & $\begin{array}{c}\text { Elastic modulus } E_{s} \\
(\mathrm{GPa})\end{array}$ \\
\hline \hline \multirow{2}{*}{ Specimens } & $8 \#$ & 4.01 & 274.11 & 377.81 & 182.01 \\
\cline { 2 - 6 } & $10 \#$ & 3.53 & 247.00 & 365.05 & 148.00 \\
\cline { 2 - 6 } & $14 \#$ & 2.21 & 261.84 & 368.74 & 134.01 \\
\hline
\end{tabular}




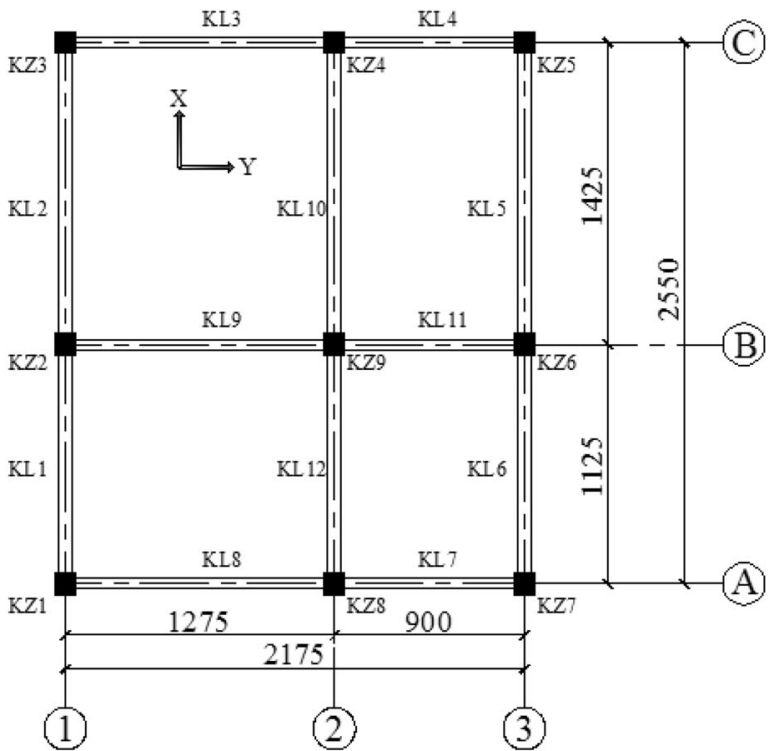

(a) Dimension in plane

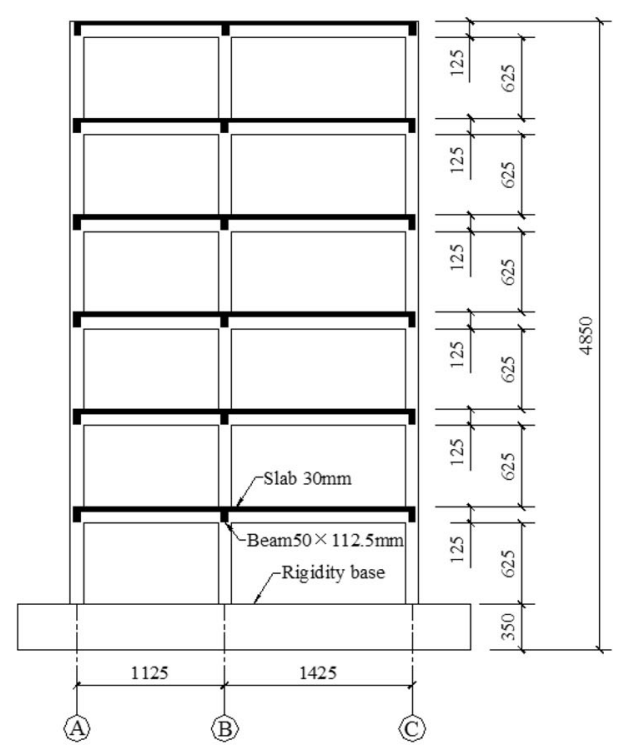

(b) Dimension in elevation

Fig. 9 Dimension of the six-storey frame.

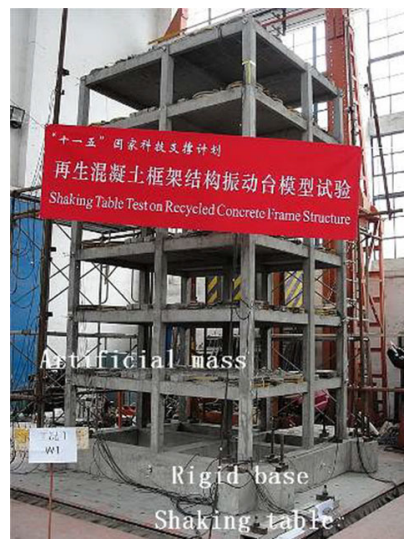

Fig. 10 RAC frame tested.

The RAC frame specimen is idealized as a three-dimensional discrete numerical model as shown in Fig. 12.

The beam and column members are modeled using the flexibility-based distributed-plasticity nonlinear fiber beamcolumn elements. For each element it is subdivided into several control sections and each section is composed of a number of fibers. The number of sections and their locations depend on the integration scheme and the desired level of accuracy. The analysis results show that, an indistinguishable indicating convergence to the analytical solution of the problem is observed for eight to ten integration points, a very good agreement with the response is obtained for four to six integration points, and the maximum force discrepancy is observed for only two integration points. In this study the Gauss-Lobatto integration scheme is used since it allows for two integration points to coincide with the end sections of the element, where significant inelastic deformations typically take place. In the numerical implementation of the RAC numerical model each nonlinear fiber beam-column element is subdivided into five integration points in order to achieve good agreement with the experimental results. The material behavior of the element depends entirely on the stress-strain relation of the fibers, which follows the unconfined and confined concrete as well as reinforcing steel models involving the strain rate effect mentioned in Sect. 2. Different concrete and steel material types can be specified for the fibers by varying the values of material parameters. Figure 13 shows the details of the section modeling for the beam and column members. Since attention is focused on the behavior of bare frames, it is assumed that floor diaphragms are infinitely rigid. The RAC frame is modeled based on the OpenSees computational platform (Mazzoni et al. 2006), a general purpose nonlinear analysis program for the static and/or dynamic analysis of complete three-dimensional structural systems.

\section{Seismic Analysis of RAC Frame Structure}

The typical responses of the structure subjected to WCW, ELW and SHW excitations are analyzed in this section. The dynamic characteristics and seismic responses obtained from the numerical simulation with and without strain rate effect are compared with the shaking table test results.

In this study, Model 1 represents RAC frame numerical model without the strain rate effect, while Model 2 represents RAC frame numerical model, in which the material models are adopted for the strain rate of $3.04 \times 10^{-2} / \mathrm{s}$ representative of seismic conditions by applying the corresponding DIF to the peak stress and the critical strain. The tested structure model is shown in Fig. 5. The total mass including live load for the frame is $17,000 \mathrm{~kg}$. The columns are assumed to be fixed at the base. The FEM used two-node fiber beam-column elements. Nine elements are used to discretize the individual columns in each storey and 12 

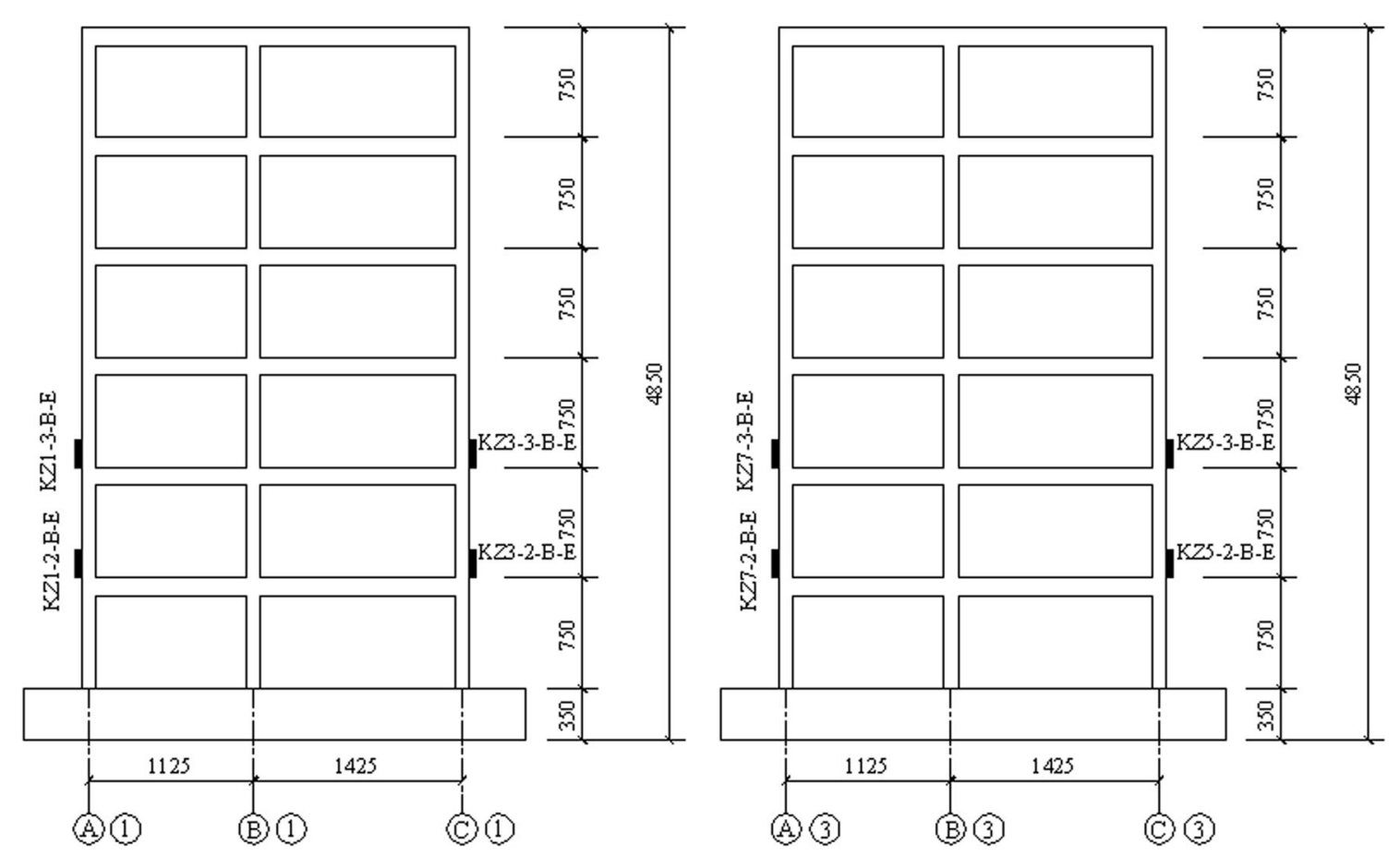

Fig. 11 Arrangement of strain sensors.

Table 3 Maximum strain rate of concrete under different test phases $\left(10^{-2} / \mathrm{s}\right)$.

\begin{tabular}{|c|c|c|c|c|c|c|c|}
\hline \multirow[t]{3}{*}{ PGA (g) } & \multicolumn{4}{|c|}{ Storey 2} & \multicolumn{3}{|c|}{ Storey 3} \\
\hline & \multicolumn{4}{|c|}{ Corner column } & \multicolumn{3}{|c|}{ Corner column } \\
\hline & KZ3 & KZ1 & KZ7 & KZ5 & KZ3 & KZ1 & KZ7 \\
\hline 0.415 & 0.59 & 0.56 & 0.67 & 1.10 & 0.76 & 3.96 & 4.76 \\
\hline 0.550 & 0.69 & 4.39 & 2.07 & 1.40 & 0.88 & 3.51 & 5.16 \\
\hline 0.750 & 0.71 & 8.25 & 3.72 & 3.40 & 0.86 & 5.53 & 6.91 \\
\hline 1.170 & 1.20 & 0.65 & 2.97 & 3.73 & 1.57 & 5.52 & 9.51 \\
\hline Mean value & & & & 3.04 & & & \\
\hline
\end{tabular}

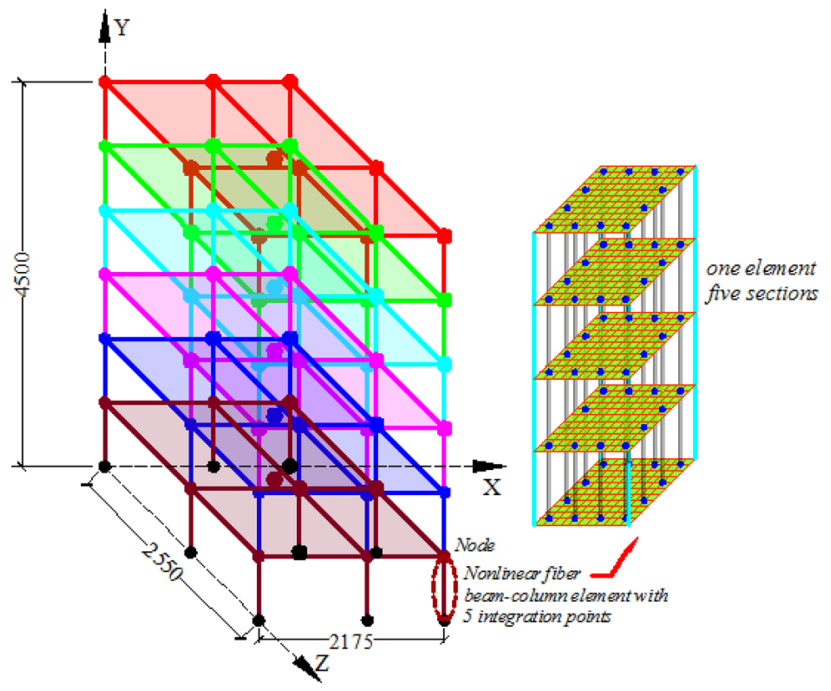

Fig. 12 Proposed modeling of RAC spatial frame.

elements the individual beams at each floor level. The same input earthquake waves and loading procedure used in the shaking table tests (Wang 2012) are followed in numerical modeling, so that the calculated and tested results can be directly compared. WCW, ELW and SHW are input horizontally in sequence in the different test phases. During earthquake motions with various intensities, typical responses of the structure are influenced more significantly for the excitation SHW than for others. Therefore, the structural responses under SHW excitation are mainly analyzed and discussed in this paper. The gradually increasing amplitudes of base excitation are input successively in a manner of timescaled earthquake waves with $0.00736 \mathrm{~s}$ intervals. Before and after each dynamic response time history analysis, a modal analysis is performed to capture the natural frequency and equivalent lateral stiffness.

\subsection{Dynamic Characteristics Analysis}

The natural vibration frequency of the structure is obtained with the white noise scanning for the shaking table tests and the modal analysis for the numerical modelling at different earthquake motions of various intensities. Table 4 lists the initial frequency of the structure before the test. 


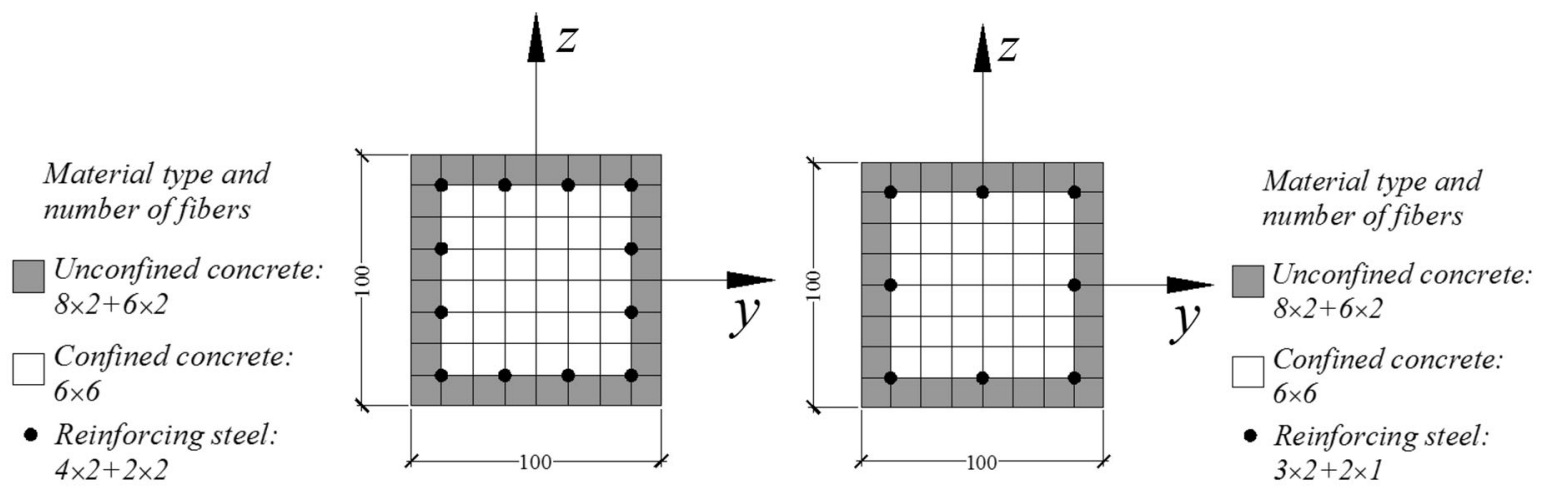

(a) Corner column

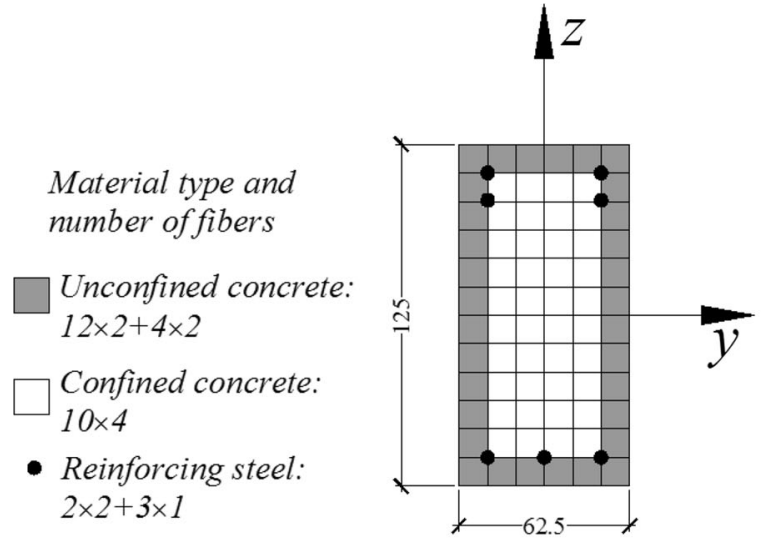

(c) Beam element in X-direction (b) Side and central column

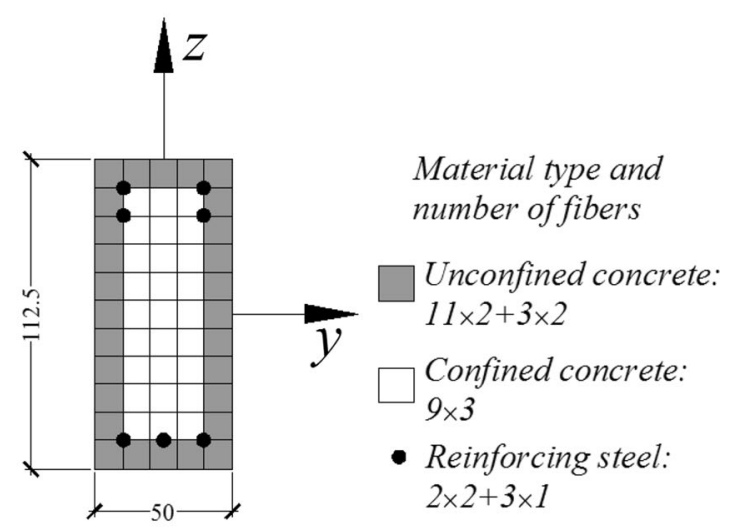

(d) Beam element in direction $Y$

Fig. 13 Subdivision of cross section into fibers for fiber beam-column element.

For the experimental results the first two modes are of translation in $\mathrm{Y}$ and $\mathrm{X}$ directions with initial natural frequency of 3.450 and $3.715 \mathrm{~Hz}$, respectively. Based on Model 1, the calculated initial natural frequencies in the Yand X-direction are 3.392 and $3.756 \mathrm{~Hz}$, respectively. Using Model 2 with strain rate effect the obtained initial natural frequencies in direction $\mathrm{Y}$ and $\mathrm{X}$ are 3.419 and $3.669 \mathrm{~Hz}$, respectively. It can be seen that the frequency from numerical simulations match test results very well.

Choosing the natural frequency $f_{0}$ under the test phase with $0.130 \mathrm{~g}$ peak acceleration amplitude as the reference, the variation of the natural frequency under WCW, ELW and SHW is shown in Fig. 14a-c, respectively. It can be seen that the natural frequency variation values obtained by Models 1 and 2 agree well with the tested model values, more closed for Model 2 than for Model 1 without the strain rate effect. The error of the natural frequency variation value increases in the severe elastic-plastic stage due to the complex attributes of the materials such as strain softening in compression and tension of RAC and tensile degradation of reinforcement steel that cannot be captured very well by the analysis procedure in the post-peak stress regime. The variation values of the simulated natural frequency for RAC frame structure under the excitations WCW, ELW and SHW are listed in Table 5. Table 5 shows that, under the $0.415 \mathrm{~g}$ test phase, the errors in the variation values $\left(f f f_{0}\right)$ for the strain rate included and exclude are respectively 5 and $18 \%$ for the excitation WCW, about 15 and $34 \%$ for the excitation ELW, about 16 and $42 \%$ for the excitation SHW.

On the other hand, when either Model 1 or Model 2 is subjected to different earthquake wave excitations, an obvious discrepancy is found. For example, for Model 1 the variation of the natural vibration frequency is 0.695 for the excitation WCW, 0.789 for the excitation ELW, and 0.853 for the excitation SHW. It is indicated that the nature of an input earthquake wave can sometimes induce a significant effect on the dynamic characteristics of the structures.

Table 4 Initial natural frequency comparison between calculated and tested results.

\begin{tabular}{c|c|c}
\hline Models & First order frequency in the X direction (Hz) & First order frequency in the Y direction (Hz) \\
\hline \hline Model 1 & 3.756 & 3.392 \\
\hline Model 2 & 3.669 & 3.419 \\
\hline Tested model & 3.715 & 3.450 \\
\hline
\end{tabular}




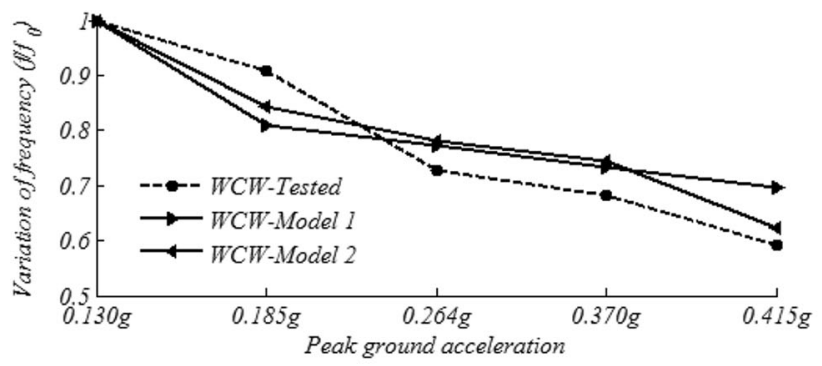

(a) Under WCW

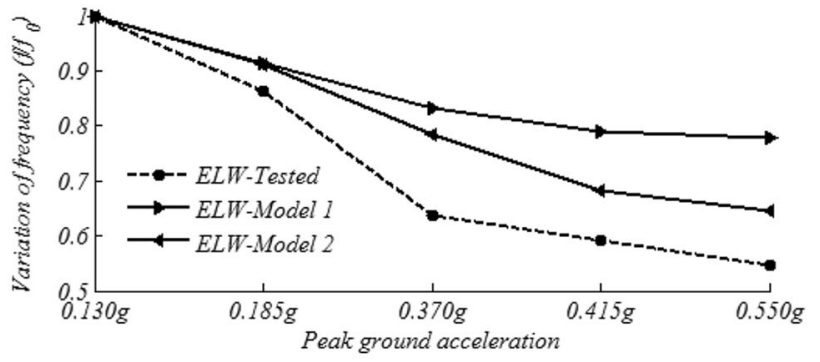

(b) Under ELW

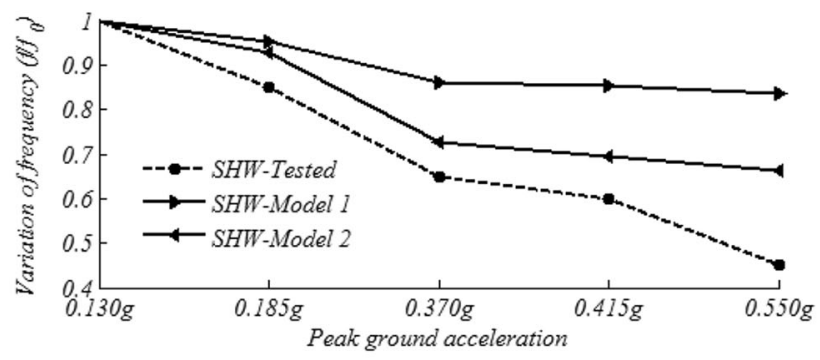

(c) Under SHW

Fig. 14 Variation of natural vibration frequency from different excitation histories.

\subsection{Seismic Response of RAC Frame Structure 4.2.1 Storey Displacement}

The simulated top displacement time histories of the RAC frame structure subjected to excitation SHW using Models 1 and 2 are compared with that of the experimental results as shown in Fig. 15. For the purpose of easier comparison, only the response history from 4 to $15 \mathrm{~s}$ is presented in the figure.
In general the inclusion or exclusion of strain rate makes little difference to the overall frequency content of the displacement response. The peak displacement for Model 1 is slightly higher than that of Model 2 and the tested model. It is also interesting to see that the peak and troughs for the three models are similarly located. It can be seen that the direction of the peak response is basically the same for the three models. For example, the maximum top displacements in the numerical models and the tested model are all negative. However, the peak values occur at different times.

The simulated storey displacement envelops of the RAC frame structure subjected to excitation SHW model are shown in Figs. 16a to $16 \mathrm{~d}$ along with that obtained from experimental results. Examining Fig. 16 it can be seen that the storey displacement distribution for Models 1 and 2 is similar to that from shaking table tests along the height, more closely for Model 2 than for Model 1. In general, the storey displacement curve along the height is found to show a shear-type feature, which is in accordance with the distribution feature of the first order vibration mode curve of the model as presented by Wang (2012). While inputting different earthquake waves, it has little influence on the shape of the structural displacement response curve but has obvious influence on the amplitude of structural displacement. The maximum storey displacement curves are relatively smooth without obvious inflexion, which means that the distribution of the equivalent rigidity along the height of the structure is well proportioned.

From Fig. 16, it can be seen that the relative errors of the storey displacement obtained using Model 2 are mostly smaller than those using Model 1. For example, the maximum relative error of the storey displacement for floors 1-6 is found to be around $-8.9 \%$ from Model 2 due to the strain rate effect, but the maximum relative error for the exclusion of the strain rate effect of Model 1 is around $42.8 \%$, under the $0.130 \mathrm{~g}$ test phase. The maximum relative error of the storey displace for floors $1-6$ is about $-16.0 \%$ from Model 2 and around $-23.2 \%$ from Model 1 , under the $0.370 \mathrm{~g}$ test phase. The maximum relative error of the storey displace for floors $1-6$ is around $-20.6 \%$ from Model 2 and about $-32.3 \%$ from Model 1 , under the $0.415 \mathrm{~g}$ test phase. The

Table 5 Natural vibration frequency variation under different test phases $\left(f l f_{0}\right)$.

\begin{tabular}{|c|c|c|c|c|c|c|c|}
\hline Wave types & Model & $0.130 \mathrm{~g}$ & $0.185 \mathrm{~g}$ & $0.264 \mathrm{~g}$ & $0.370 \mathrm{~g}$ & $0.415 \mathrm{~g}$ & $0.550 \mathrm{~g}$ \\
\hline \multirow[t]{3}{*}{ WCW } & Model 1 & 1.000 & 0.809 & 0.771 & 0.733 & 0.695 & 0.685 \\
\hline & Model 2 & 1.000 & 0.842 & 0.780 & 0.745 & 0.622 & 0.590 \\
\hline & Test model & 1.000 & 0.909 & 0.727 & 0.682 & 0.591 & 0.545 \\
\hline \multirow[t]{3}{*}{ ELW } & Model 1 & 1.000 & 0.914 & 0.872 & 0.832 & 0.789 & 0.779 \\
\hline & Model 2 & 1.000 & 0.911 & 0.831 & 0.784 & 0.682 & 0.644 \\
\hline & Test model & 1.000 & 0.864 & 0.727 & 0.637 & 0.591 & 0.545 \\
\hline \multirow[t]{3}{*}{ SHW } & Model 1 & 1.000 & 0.954 & - & 0.861 & 0.853 & 0.834 \\
\hline & Model 2 & 1.000 & 0.928 & - & 0.725 & 0.694 & 0.664 \\
\hline & Test model & 1.000 & 0.8500 & - & 0.650 & 0.600 & 0.450 \\
\hline
\end{tabular}




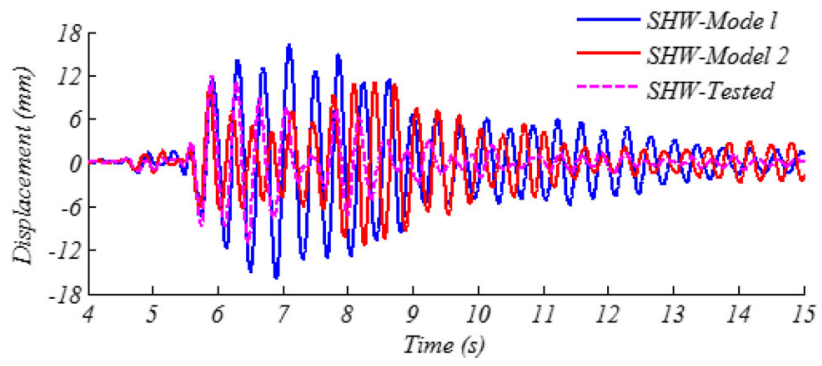

Fig. 15 Top displacement history of RAC frame structure under $0.130 \mathrm{~g}$ test phase.

maximum relative error of the storey displacement for floors $1-6$ is about $-11.9 \%$ from Model 2 and around $-28.0 \%$ from Model 1, under the $0.550 \mathrm{~g}$ test phase. It can be seen that while the relative errors of the storey displacement for floors 4-6 from Model 2 are smaller than these from Model 1 , the relative errors of the storey displacement for the floors 1-3 from Model 2 are slightly larger than these from Model 1. In general, it is indicated that Model 2 considering the strain rate effect of the material is more likely to provide a better match between the numerical simulation and the dynamic tests as the key attributes of the seismic behavior of the structure are captured by the model. On the other hand, it is worthy to note that the storey displacement response for the tested model is slightly larger than that the other two numerical models in the post-elastic regime. This can be explained that in the degradation stage of the lateral stiffness for the real structure is more significant than due to inclusion or exclusion of the strain rate for the numerical simulation.

\subsubsection{Capacity Curves}

The base shear versus top deformation capacity curves for both cases with and without strain rate effect are compared and discussed along with the experimental results as shown in Fig. 17. By examining Fig. 17, it can be seen that the capacity curves during earthquake motion excitation with PGAs from 0.066 to $1.170 \mathrm{~g}$ for both Models 1 and 2 are similar to that from shaking table tests, more closely for Model 2 than for Model 1. Simultaneously, while the

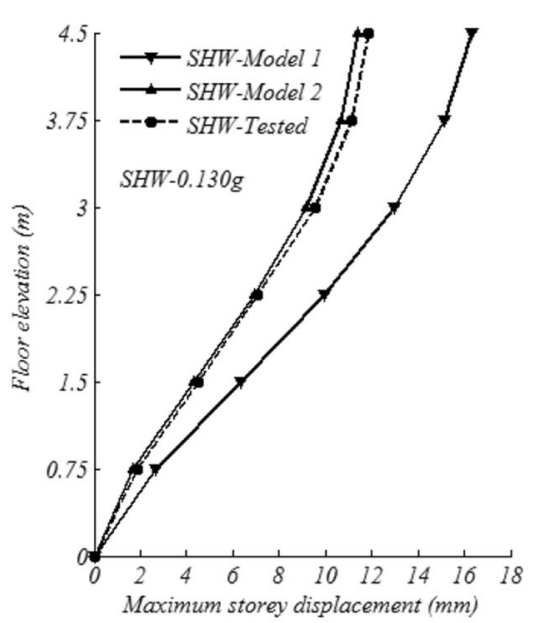

(a) $0.130 g$

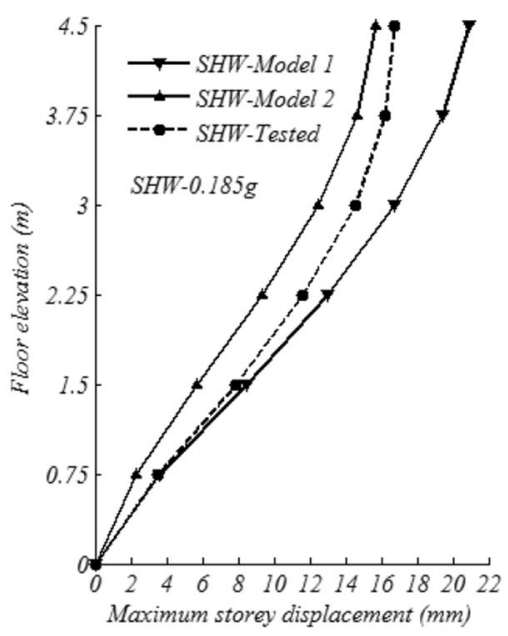

(b) $0.185 g$

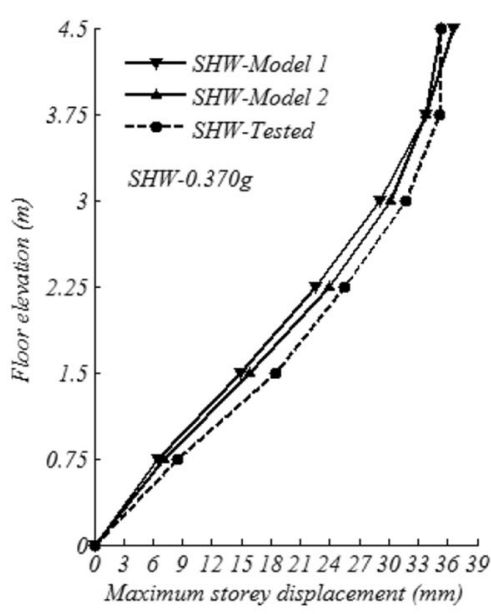

(c) $0.370 g$

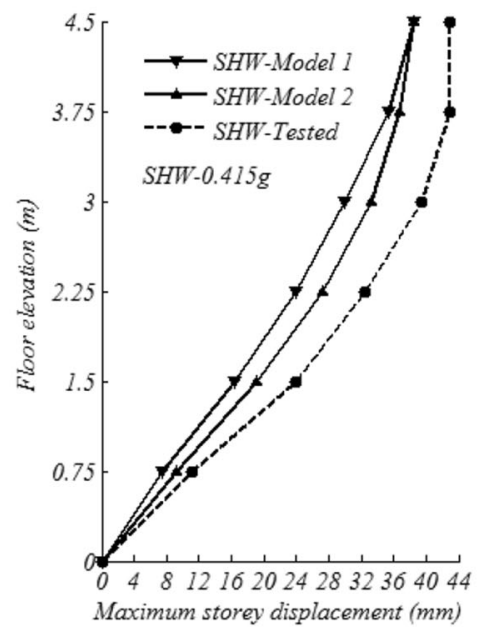

(d) $0.415 g$

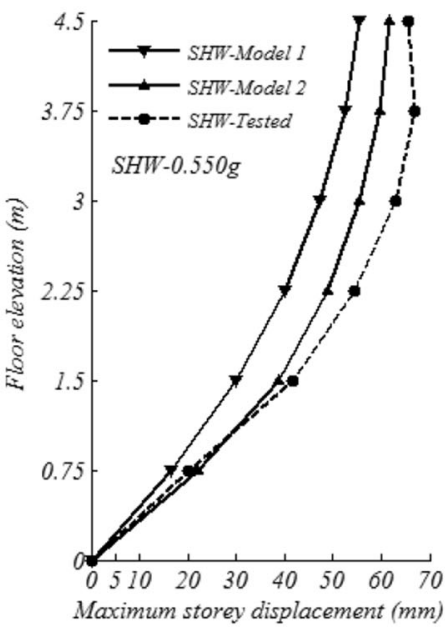

(e) $0.550 g$

Fig. 16 Envelope of storey displacement with various intensities. 
capacity curves from Models 1 and 2 match the experimental curves closely in particular for the latter with the inclusion of the strain rate effect in the early test phase, the error increases for the capacity curves in the post-yield regime of the structures for both Models 1 and 2.

\section{Parameter Study for Varying Strain Rate}

In this section, for the motivation to examine how the seismic behaviors of the RAC structure vary in a real seismic situation for different strain rates, the strain rates of $3.04 \times 10^{-5}, 3.04 \times 10^{-3}, 3.04 \times 10^{-2}$ and $3.04 \times 10^{-1} /$ $\mathrm{s}$, which are regarded as being indicative of the strain rate expected during the response of reinforced concrete to earthquakes, are taken into account in the numerical simulation, respectively. Here, the typical seismic response for the model with strain rate of $3.04 \times 10^{-5} / \mathrm{s}$ are defined as the quasi-static response and used as the reference values of the structural responses. Once again the six-storey two-span and two-bay RAC frame structure discussed earlier is used. For easy comparison of the seismic responses under dynamic loads with different strain rates included in this section the DIF is defined as the ratio of dynamic response value to quasi-static response value.

\subsection{Storey Displacement}

The storey displacement response of the structure subjected to earthquake excitations and modeled using the verified model proposed with strain rates effect are shown in Figs. 18a to $18 \mathrm{f}$. The figures show that the inclusion of strain rate makes little difference to the overall storey displacement distribution of the structure along the height. However, the amplitude quantities for different cases obviously suffer a significant influence.

Comparisons for the storey displacements under different strain rates show two important features as follows: firstly, the storey displacements vary slightly in the trend of decreasing with the increasing strain rate. For example, in the $0.066 \mathrm{~g}$ test phase the DIFs of the top deformation are $0.964,0.949$ and 0.935 under the earthquake excitation history WCW with the strain rate of $3.04 \times 10^{-3}$,

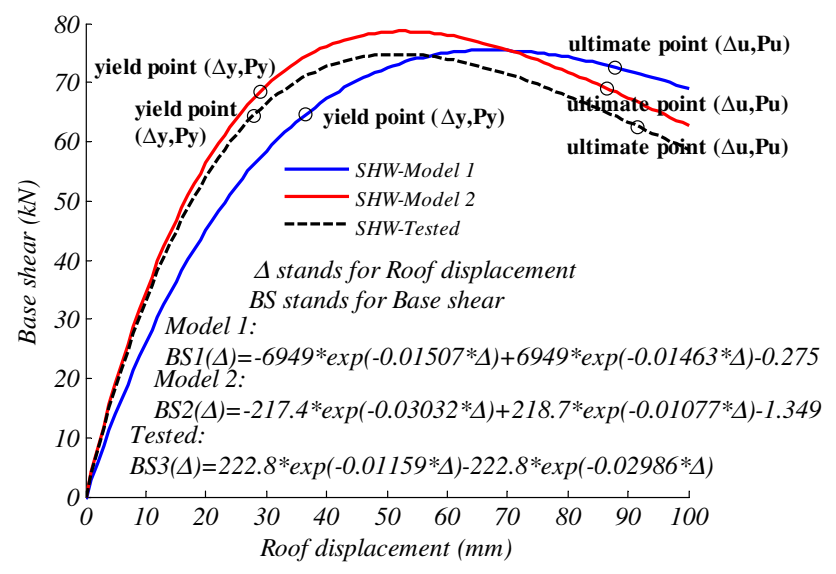

Fig. 17 Fitting function model for the capacity curves.
$3.04 \times 10^{-2}$ and $3.04 \times 10^{-1} / \mathrm{s}$, respectively. In the $0.130 \mathrm{~g}$ test phase the DIFs of the top deformation are $0.948,0.946$ and 0.884 under the earthquake excitation history SHW with the strain rate of $3.04 \times 10^{-3}, 3.04 \times 10^{-2}$ and $3.04 \times 10^{-1} / \mathrm{s}$, respectively. In the $0.185 \mathrm{~g}$ test phase the DIFs of the top deformation are $0.916,0.877$ and 0.788 under the earthquake excitation history WCW with the strain rate of $3.04 \times 10^{-3}, 3.04 \times 10^{-2}$ and $3.04 \times 10^{-1} / \mathrm{s}$, respectively. Secondly, the storey displacements vary obviously in the trend of decreasing with the increasing input acceleration amplitudes. For example, for the strain rate of $3.04 \times 10^{-1} / \mathrm{s}$ the DIFs of the top deformation are 0.935 , $0.884,0.788$, and 0.702 under the test phases with PGA of $0.066,0.130,0.185$ and $0.370 \mathrm{~g}$, respectively. On the other hand, it is interesting to note that, in the post-yield regime (e.g., the test phases from 0.415 to $0.550 \mathrm{~g}$ ) variation of the maximum storey deformation response due to the strain rate is unconspicuous with the increasing input acceleration amplitudes.

\subsection{Storey Shear Force}

The base shear response of the structure subjected to earthquake excitation history SHW and modeled using the proposed model in this study are shown in Fig. 19. The figure shows that the inclusion of strain rate makes little difference to the curve distribution of the base shear against the PGA for the RAC structure. However, the magnitude of the base shear for different loading cases by varying strain rates obviously suffers a significant influence, i.e., the base shear of the RAC structure under dynamic loading conditions increases with gradually increasing amplitude of strain rate. Analyzing the base shear versus PGA curves, it can be demonstrated that the base shear augments steeply with the increasing input acceleration amplitudes at the cracking regime with the PGAs from 0.130 to $0.370 \mathrm{~g}$. The base shear increases flatly with the increasing input acceleration amplitudes at the yield regime with the PGAs from 0.370 to $0.550 \mathrm{~g}$, at the yield regime the strain of the RAC in compression steps into hardening stage. For the ultimate regime, with the PGAs from 0.550 to $0.750 \mathrm{~g}$, the base shear decreases flatly with the increasing input acceleration amplitudes, then the base shear decreases steeply up to the PGA of $1.170 \mathrm{~g}$, at the ultimate regime the strain of the RAC in comparison steps into softening stage.

Based on the information presented in Fig. 19, the fitting curves for the base shear versus PGA of the RAC frame structure under dynamic loads with different strain rates included are plotted in Fig. 20. The corresponding fitting polynomial function model derived from the information shown in Fig. 20 for each fitting curve is expressed as follows:

$$
B S_{i}(P G A)=a_{i} \cdot(P G A)^{3}-b_{i} \cdot(P G A)^{2}+c_{i} \cdot(P G A)+d_{i}
$$

Here, the $P G A$ as the independent variable of the function is assigned at the interval $\left[\begin{array}{lll}0.130 & 1.170 \mathrm{~g}\end{array}\right]$ with $\mathrm{g}\left(9.8 \mathrm{~m} / \mathrm{s}^{2}\right)$ as the fundamental unit. $B S_{i}(i=1,2,3,4)$ denotes the base 


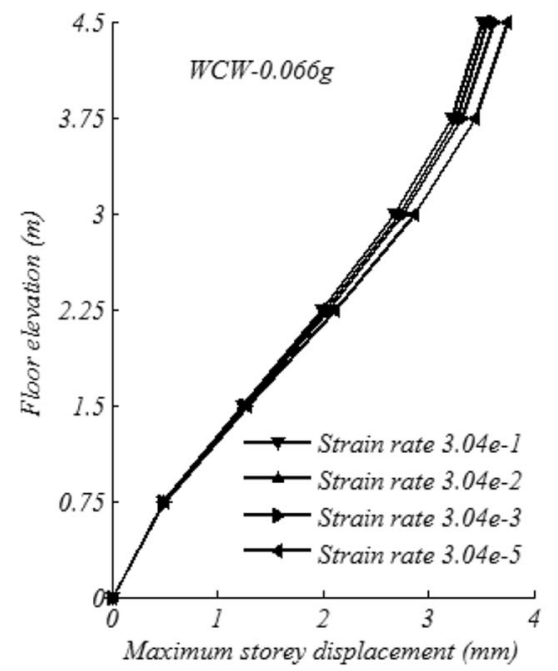

(a) $0.066 g$

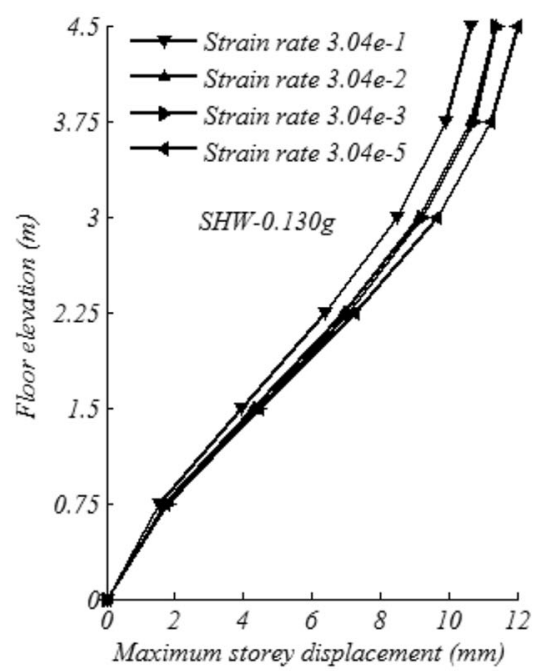

(b) $0.130 g$

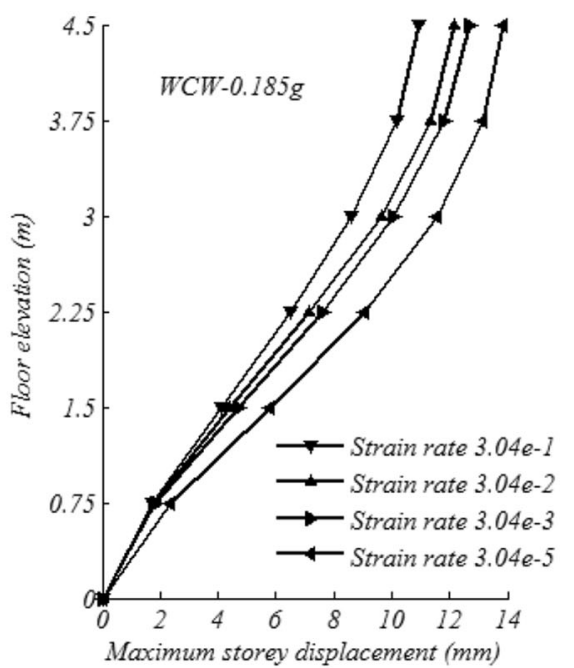

(c) $0.185 g$

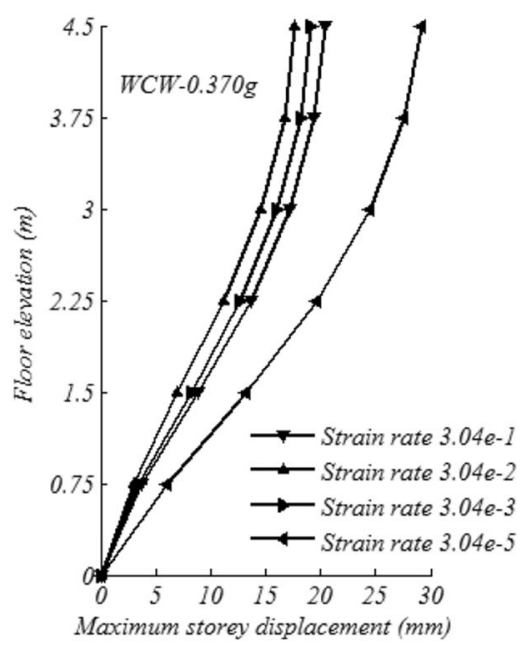

(d) $0.370 g$

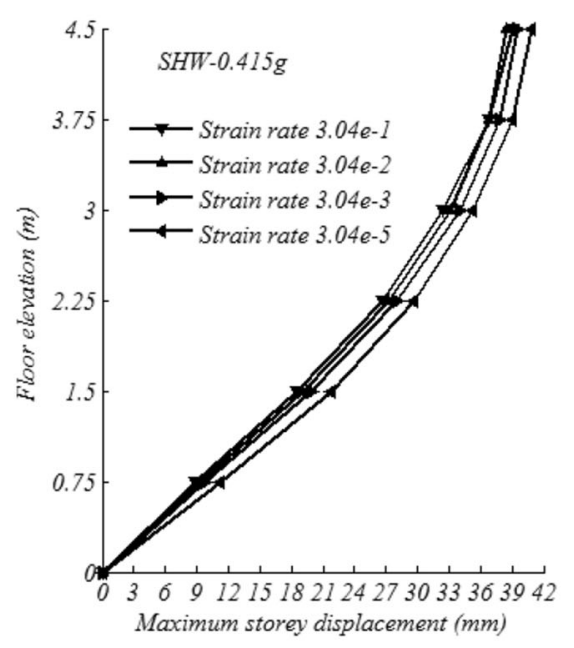

(e) $0.415 g$

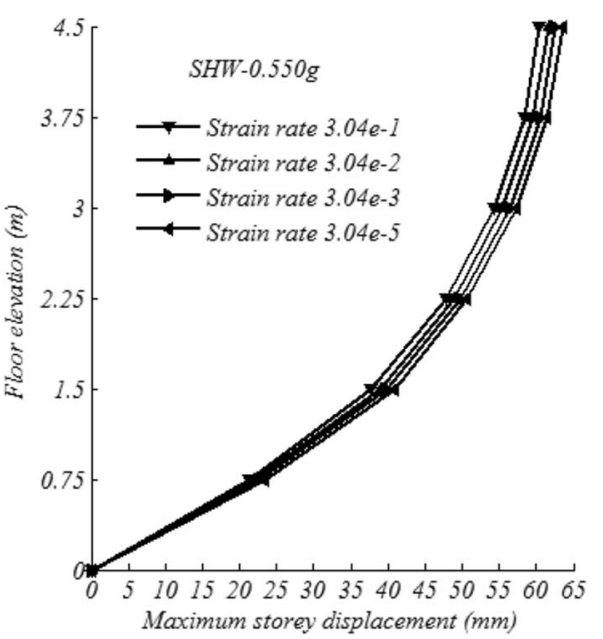

(f) $0.550 \mathrm{~g}$

Fig. 18 Storey displacement envelop of the RAC with different strain rates included.

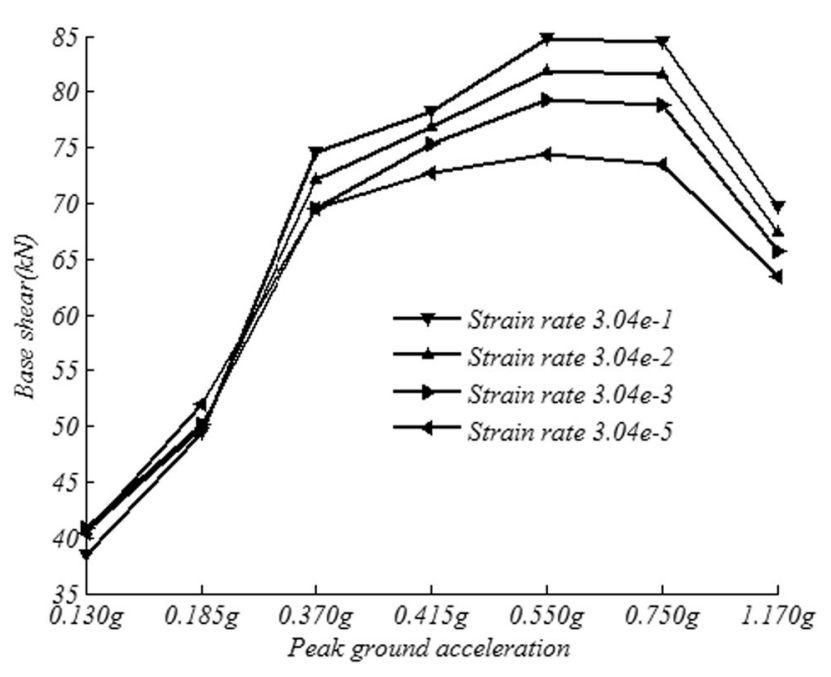

Fig. 19 Base shear distribution with different strain rates included.

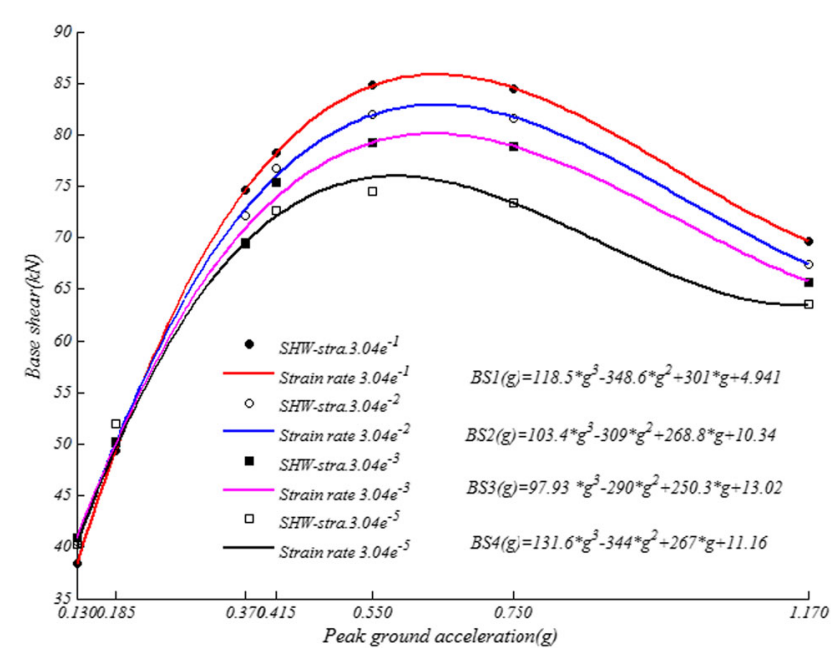

Fig. 20 Fitting function curves for the base shear with different strain rates included. 
Table 6 Parameters of the equations used for fitting the base shear versus PGA curves.

\begin{tabular}{c|c|c|c|c}
\hline \multicolumn{2}{|c|}{ Parameters } & \multicolumn{2}{c}{ Curve equations } \\
\hline \hline$a_{i}$ & $b_{i}$ & $c_{i}$ & $d_{i}$ & \\
\hline 118.5 & -348.6 & 301 & 4.941 & $B S_{1}$ \\
\hline 103.4 & -309 & 268.8 & 10.34 & $B S_{2}$ \\
\hline 97.93 & -290 & 250.3 & 13.02 & $B S_{3}$ \\
\hline 131.6 & -344 & 267 & 11.16 & $B S_{4}$ \\
\hline
\end{tabular}

shear with strain rate of $3.04 \times 10^{-1}, 3.04 \times 10^{-2}$, $3.04 \times 10^{-3}$ and $3.04 \times 10^{-5} / \mathrm{s}$, respectively. $a_{i}, b_{i}, c_{i}$ and $d_{i}$ represent the function model parameters $(i=1,2,3,4)$. The results of the fitting are presented in Table 6 .

\section{Summary and Conclusions}

The dynamic characteristics and the seismic behaviors of the RAC frame structure are analyzed and discussed by examining the FE models with and without considering the strain rate effect, and compared with the shaking table test results. For the purpose to examine how the seismic behaviors of the RAC frame structure vary under different strain rates in a real seismic situation, a numerical simulation is performed by varying the parameters of strain rate. Several typical conclusions are summarized and presented as follows:

(1) The natural frequency variation values obtained from Models 1 and 2 agree well with the experimentally measured values, and Model 2 with strain rate effect performs better than Model 1 without strain rate effect. The error increases for the natural frequency variation value in the severe elastic-plastic stage. This can be partially attributed to the complex attributes of the materials such as strain softening in compression and tension of RAC and tensile degradation of reinforcement steel that cannot be captured very well by the analysis procedure in the post-elastic regime.

(2) The seismic responses for Models 1 and 2 agree well with the tested model values, with Model 2 giving better predictions than Model 1. Model 2 considering the strain rate effect of the material is more likely to provide a better match between the numerical simulation and the dynamic tests as the key attributes of the seismic behavior of the structure are captured by the model.

(3) The storey deformations of the RAC frame structure subjected to dynamic loads of the lower strain rate are consistently larger than those subjected to dynamic loads of the higher strain rate, because of the inclusion of the strain rate effect on the peak strain of the RAC and the yield strain of reinforcement steel.

(4) The base shear decreases slightly with the increasing strain rate of RAC in the cracking regime. However, the base shear increases slightly with the increasing strain rate of RAC in the yield and ultimate regime.
This can be attributed to the inclusion of the strain rate effect on the peak strength of the RAC and yield strength of the reinforcement steel.

\section{Acknowledgments}

The authors wish to acknowledge the financial support from Project funded by China Postdoctoral Science Foundation through Grant Nos. 2014M550247 and 2015T80449, the National Natural Science Foundation of China (51438007), and the Key Projects of Science and Technology Pillar Program of Henan Province (152102310027).

\section{Open Access}

This article is distributed under the terms of the Creative Commons Attribution 4.0 International License (http:// creativecommons.org/licenses/by/4.0/), which permits unrestricted use, distribution, and reproduction in any medium, provided you give appropriate credit to the original author(s) and the source, provide a link to the Creative Commons license, and indicate if changes were made.

\section{References}

Abrams, D. A. (1917). Effect of rate of application of load on the compressive strength of concrete. ASTM Journal, 17, 364-377.

ACI Committee 555. (2002). Removal and reuse of hardened concrete. ACI Material Journal, 99(3), 300-325.

Ajdukiewicz, A. B., \& Kliszczewicz, A. T. (2007). Comparative tests of beams and columns made of recycled aggregate concrete and natural aggregate concrete. Journal of Advanced Concrete Technology, 5(2), 259-273.

Atchley, B. L., \& Furr, H. L. (1967). Strength and energyabsorption capabilities of plain concrete under dynamic and static loading. ACI Journal Proceedings, 64(11), 745-756.

Bertero, V. V., Aktan, A. E., Charney, F. A., \& Sause, R. (1984). Earthquake simulation tests and associated studies of a $1 /$ 5 th scale model of a 7-story RC test structure. U.S.-Japan cooperative earthquake research program, report no. UCB/ EERC-84/05. Berkeley, CA: Earthquake Engineering Research Center, University of California. 
Bischoff, P. H., \& Perry, S. H. (1991). Compressive behavior of concrete at high strain rates. Materials and Structures, 24(6), 425-450.

Cadoni, E., Labibes, K., \& Albertini, C. (2001). Strain-rate effect on the tensile behaviour of concrete at different relative humidity levels. Materials and Structures, 235(34), 21-26.

Chang, K. C., \& Lee, G. C. (1987). Strain rate effect on structural steel under cyclic loading. Journal of Engineering Mechanics, ASCE, 113(9), 1292-1301.

Chen, X. D., Wu, S. X., \& Zhou, J. K. (2013). Experimental and modeling study of dynamic mechanical properties of cement paste, mortar and concrete. Construction and Building Materials, 47, 419-430.

Cotsovos, D. M., \& Pavlovic, M. N. (2006). Simplified FE model for RC structures under earthquakes. Structure Buildings, 159, 87-102.

Cotsovos, D. M., \& Pavlovic, M. N. (2008). Numerical investigation of concrete subjected to high rates of uniaxial tensile loading. International Journal of Impact Engineering, 35, 319-335.

Fathifazl, G., Razaqpur, A. G., Isgor, O. B., Abbas, A., Fournier, B., \& Foo, S. (2009). Flexural performance of steelreinforced recycled concrete beams. ACI Structural Journal, 106(6), 858-867.

Filippou, F. C., D’Ambrisi, A., \& Issa, A. (1992). Nonlinear static and dynamic analysis of reinforced concrete subassemblages. Report No. UCB/EERC-92/08. Berkeley, $\mathrm{CA}$ : Earthquake Engineering Research Center, University of California.

GB 50011. (2010). Code for seismic design of buildings. Beijing, China: Chinese Building Press.

Hansen, T. C. (1986). Recycled aggregate and recycled aggregate concrete, second state-of-the-art report, developments from 1945-1985. Materials and Structures, 111, 201-246.

Hognestad, E. (1951). A study of combined bending and axial load in reinforced concrete. Bulletin series 339, Illinois (USA), University of Illinois Experiment Station.

Kent, D. C., \& Park, R. (1971). Flexural members with confined concrete. Journal of the Structural Division, ASCE, 97(ST7), 1969-1990.

Kulkarni, S. M., \& Shah, S. P. (1998). Response of reinforced concrete beams at high strain rates. ACI Structural Journal, 95(6), 705-715.

Lai, J., \& Sun, W. (2009). Dynamic behavior and visco-elastic modeling of ultra-high performance cementitious composite. Cement Concrete Research, 39, 1044-1051.

Le, N. H., \& Bailly, P. (2000). Dynamic behaviour of concrete: The structural effects on compressive strength increase. Mechanics of Cohesive-Frictional Materials, 5(6), 491-510.

Li, M., \& Li, H. N. (2012). Effects of strain rate on reinforced concrete structure under seismic loading. Advances in Structural Engineering, 15(3), 461-475.

Lin, F., Gu, X. L., Kuang, X. X., \& Yin, X. J. (2008). Constitutive models for reinforcing steel bars under high strain rates. Journal of Building Materials, 11(1), 14-20.
Lu, Y. B., Chen, X., Teng, X., \& Zhang, S. (2014). Dynamic compressive behavior of recycled aggregate concrete based on split Hopkinson pressure bar tests. Latin American Journal of Solids and Structures, 11(1), 131-141.

Malvar, L. J., \& Crawford, J. E. (1998). Dynamic increase factors for steel reinforcing bars. In Proceedings of the twenty-eighth DoD explosives safety seminar, Orlando, FL, USA.

Malvar, L. J., \& Ross, C. A. (1998). Review of strain rate effects for concrete in tension. ACI Materials Journal, 95(6), 435-439.

Mazzoni, S., Mckenna, F., Scott, M. H., \& Fenves, G. L. (2006). Open system for earthquake engineering simulation, user command-language manual. Berkeley, CA: Pacific Earthquake Engineering Research Center, University of California.

Norris, C. H., Hansen, R. J., Holley, M. J., Biggs, J. M., Namyet, S., \& Minasmi, J. K. (1959). Structural design for dynamic loads. New York, NY: McGraw-Hill.

Oh, B. H. (1987). Behavior of concrete under dynamic tensile loads. ACI Materials Journal, 84(1), 8-13.

Pandey, A. K., Kumar, R., Paul, D. K., \& Trikha, D. N. (2006). Strain rate model for dynamic analysis of reinforced concrete structures. Journal of Structural Engineering, ASCE, 132(9), 1393-1401.

Restrepo-Posada, J. I., Dodd, L. L., Park, R., \& Cooko, N. (1994). Variables affecting cyclic behavior of reinforcing steel. Journal of Structural Engineering, ASCE, 120(11), 3178-3196.

Scott, B. D., Park, R., \& Priestley, M. J. N. (1982). Stress-strain behavior of concrete confined by overlapping hoops at low and high strain rates. ACI Journal, 79(1), 13-27.

Shing, P. S. B., \& Mahin, S. A. (1988). Rate of loading effects on pseudo dynamic tests. Journal of Structural Engineering, ASCE, 114(11), 2403-2420.

Soroushian, P., \& Choi, K. B. (1987). Steel mechanical properties at different strain rates. Journal of Structural Engineering, ASCE, 113(4), 663-672.

Taucer, F. F., Spacone, E., \& Filippou, F. C. (1991). A fiber beam-column element for seismic response analysis of reinforced concrete structures. Report no. UCB/EERC-91/ 17. Berkeley, CA: Earthquake Engineering Research Center, University of California.

The Euro-International Committee for Concrete (CEB). (1993). CEB-FIP model code 1990. Lausanne: Thomas Telford Ltd.

Wakabayashi, M., Nakamura, T., Iwai, S., \& Hayashi, Y. (1984). Effect of strain rate on the behavior of structural members subjected to earthquake force. In Proceeding 8th world conference on earthquake engineer, San Francisco, CA (pp. 491-498).

Wang, C. Q. (2012). Research on shaking table test and nonlinear analysis for recycled aggregate concrete frame structure. PhD Thesis, College of Civil Engineering, Tongji University, Shanghai, China.

Wang, C. Q., \& Xiao, J. Z. (2012). Shaking table tests on a recycled concrete block masonry building. Advances in Structural Engineering, 15(10), 1843-1860. 
Xiao, J. (2008). Recycled concrete. Beijing, China: Chinese Building Press. (in Chinese).

Xiao, S., Li, H., \& Lin, G. (2008). Dynamic behaviour and constitutive model of concrete at different strain rates. Magazine of Concrete Research, 60(4), 271-278.

Xiao, J. Z., Li, L., Shen, L. M., \& Poon, C. S. (2015). Compressive behaviour of recycled aggregate concrete under impact loading. Cement and Concrete Research, 71, 46-55.

Xiao, J. Z., Li, J. B., \& Zhang, C. (2005). Mechanical properties of recycled aggregate concrete under uniaxial loading. Cement and Concrete Research, 35, 1187-1194.

Xiao, J. Z., Wang, C. Q., Li, J., \& Tawana, M. M. (2012a). Shake-table model tests on recycled aggregate concrete frame structure. ACI Structural Journal, 109(6), 777-786.

Xiao, J. Z., Xie, H., \& Yang, Z. (2012b). Shear transfer across a crack in recycled aggregate concrete. Cement and Concrete Research, 42(5), 700-709.

Xiao, J. Z., Yuan, J. Q., \& Li, L. (2014). Experimental study on dynamic mechanical behavior of modeled recycled aggregate concrete under uniaxial compression. Journal of Building Structures, 35(3), 201-207. (in Chinese).

Yassin, M., \& Hisham, M. (1994). Nonlinear analysis of prestressed concrete structures under monotonic and cyclic load. PhD Thesis, University of California, Berkeley, CA.

Zhang, J. W., Cao, W. L., Meng, S. B., Yu, C., \& Dong, H. Y. (2014). Shaking table experimental study of recycled concrete frame-shear wall structures. Earthquake Engineering and Engineering Vibration, 13(2), 257-267.

Zhou, X. Q., \& Hao, H. (2008). Modelling of compressive behaviour of concrete-like materials at high strain rate. International Journal of Solids and Structures, 45, 4648-4661.

Zielinski, A. J., Reinhardt, H. W., \& Körmeling, H. A. (1981). Experiments on concrete under uniaxial impact tensile loading. Materials and Structures, 80(14), 103-112. 